\title{
Lignin: Drug/Gene Delivery and Tissue Engineering Applications
}

This article was published in the following Dove Press journal:

International Journal of Nanomedicine

\author{
Raj Kumar,' Arun Butreddy, ${ }^{2}$ \\ Nagavendra Kommineni, (iD) ${ }^{3}$ \\ Pulikanti Guruprasad Reddy, \\ Naveen Bunekar, ${ }^{5}$ \\ Chandrani Sarkar, (iD ${ }^{6}$ Sunil Dutt, ${ }^{7}$ \\ Vivek K Mishra, iD ${ }^{8}$ \\ Keshaw Ram Aadil, ${ }^{9}$ \\ Yogendra Kumar Mishra, (DD ${ }^{10}$ \\ David Oupicky,' Ajeet Kaushik (D) "I
}

'Center for Drug Delivery and Nanomedicine, Department of Pharmaceutical Sciences, University of Nebraska Medical Center, Omaha, NE, 68198, USA; ${ }^{2}$ Formulation R\&D, Biological E. Limited, IKP Knowledge Park, Hyderabad, Telangana State, 500078, India; ${ }^{3}$ College of Pharmacy and Pharmaceutical Sciences, Florida Agricultural and Mechanical University, Tallahassee, FL, 32307, USA; ${ }^{4}$ Department of Chemistry, Indian Institute of Science Education and Research (IISER)-Tirupati, Tirupati, 5I7507, Andhra Pradesh, India; ${ }^{5}$ Department of Chemistry, Chung Yuan Christian University, Chung Li, 32023, Taiwan; ${ }^{6}$ Department of Chemistry, Mahila College, Kolhan University, Chaibasa, Jharkhand, 833202, India;

${ }^{7}$ Department of Chemistry, Govt. Post Graduate College, Una, Himachal Pradesh, India; ${ }^{8}$ Independent Researcher, Groningen, The Netherlands; ${ }^{9}$ Center for Basic Sciences, Pt. Ravishankar Shukla University, Raipur, 4920I0, Chhattishgarh, India; ${ }^{10}$ Mads Clausen Institute, NanoSYD, University of Southern Denmark, Sønderborg, 6400, Denmark; "'NanoBioTech Laboratory, Health Systems Engineering, Department of Natural Sciences, Division of Sciences, Art, \& Mathematics, Florida Polytechnic University, Lakeland, FL, 33805, USA

Correspondence: David Oupicky Center for Drug Delivery and Nanomedicine, Department of Pharmaceutical Sciences, University of Nebraska Medical Center, Omaha, NE, 68198, USA

Email david.oupicky@unmc.edu

Ajeet Kaushik

NanoBioTech Laboratory, Health Systems Engineering, Department of Natural Sciences, Division of Sciences, Art, \& Mathematics, Florida Polytechnic University, Lakeland, FL, 33805, USA

Email ajeet.npl@gmail.com

\begin{abstract}
Lignin is an abundant renewable natural biopolymer. Moreover, a significant development in lignin pretreatment and processing technologies has opened a new window to explore lignin and lignin-based bionanomaterials. In the last decade, lignin has been widely explored in different applications such as drug and gene delivery, tissue engineering, food science, water purification, biofuels, environmental, pharmaceuticals, nutraceutical, catalysis, and other interesting low-valueadded energy applications. The complex nature and antioxidant, antimicrobial, and biocompatibility of lignin attracted its use in various biomedical applications because of ease of functionalization, availability of diverse functional sites, tunable physicochemical and mechanical properties. In addition to it, its diverse properties such as reactivity towards oxygen radical, metal chelation, renewable nature, biodegradability, favorable interaction with cells, nature to mimic the extracellular environment, and ease of nanoparticles preparation make it a very interesting material for biomedical use. Tremendous progress has been made in drug delivery and tissue engineering in recent years. However, still, it remains challenging to identify an ideal and compatible nanomaterial for biomedical applications. In this review, recent progress of lignin towards biomedical applications especially in drug delivery and in tissue engineering along with challenges, future possibilities have been comprehensively reviewed.

Keywords: lignin, biopolymer, drug delivery, biomedical engineering, nano-biosystem,
\end{abstract} nanomedicine, tissue engineering

\section{Introduction}

Lignin means lignum which is a Latin word, and it is an important constituent of the natural lignocellulosic polymers consist of coniferyl alcohol, p-coumaryl alcohol, and sinapyl alcohol as the three basic structural units. ${ }^{1}$ Lignin is a linear polyphenolic, amorphous, and most abundant biopolymer after cellulose which is being potentially utilized in drug delivery. It has various advantages such as biodegradability, antimicrobial property, ease of availability among other polymers. Lignin is the second most highly branched renewable biomacromolecule (molar mass typically in the range of 1000-2000 $\mathrm{g} \mathrm{mol}^{-1}$ ) after cellulose, which has been found mostly in vascular cellular plants including herbs and grasses. ${ }^{2-7}$ Not surprisingly, compared to other biomass components obtained from plants including carbohydrates, proteins, fats, vitamins, flavors, dyes, etc., the lignin has a complicated structure with an amorphous character, that has built with the repeating cross-linked phenylpropanoid units of three basic monomer units namely cumaryl, coniferyl, and sinapyl alcohol. ${ }^{3,8}$ Lignin was extracted from various sources of biomass (wood biomass, trees, wheat straw, prairie cordgrass, switchgrass, and corn stover) following kraft, sulfite, soda, and organosolv processing methods. 3,4 
The global production of lignin-based materials as byproducts from wood hydrolysis and pulp industries exceeds 50 million tons per annum. ${ }^{9}$ Out of it, the majority of lignin was used as bio-fuel for low-value-added energy applications related to heat and electricity production or simply discarded as waste. ${ }^{9}$ Other promising commercial applications of lignin include is binders, fillers, additives, dispersants, adsorbents, and surfactants. ${ }^{10,11}$ However, in the current trends, the utility of lignin-based nanomaterials have been extended into antioxidants, anti-microbial agents, drug and gene carriers, wound healing materials, adhesives, UV protecting agents, etc., predominantly because of their promising properties including biodegradability, reactivity, biocompatibility, and other physicochemical properties. ${ }^{12,13}$ Recently, the use of lignin in the biomedical application such as drug delivery and tissue engineering are gaining significant interest (Figure 1A and B). ${ }^{14}$ Figure $1 \mathrm{~A}$ presents the progress in research articles number about lignin and Figure 1B presents the increase of lignin use in diverse fields. ${ }^{14}$

In recent years, lignin has gained considerable attention from researchers. They are understanding the existing properties and exploring the new physicochemical behavior of lignin and applying it in diverse applications ranging from materials science, drug delivery, tissue engineering, food science, biofuel, skin products, catalysis, and energy. Henceforth, the quantity of research particularly in the biomedical use of lignin expanding quickly (Figure 1A and B) ${ }^{14}$ Despite this fact, there are several reports have been published on lignin in drug delivery, antimicrobial agents, and tissue engineering applications. ${ }^{15-17}$ However, a very limited number of review articles describing the use of lignin in biomedical applications have barely been discussed. In addition to it, In our recent report, we have

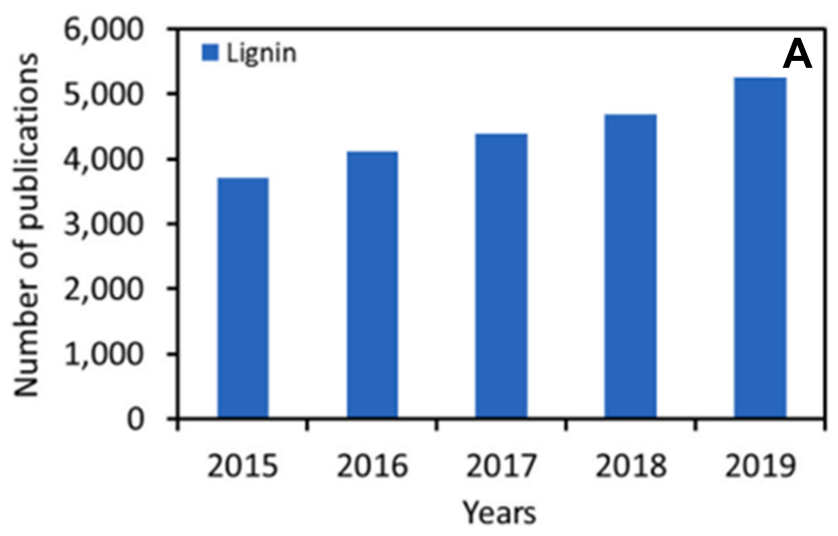

discussed chemical composition, physical-chemical properties, and extraction methods of lignin. We comprehensively described the advantages and limitations of chemical modification of lignin with inorganic nanocomposites/nanomaterials. ${ }^{18}$ Furthermore, we found that there is a high demand to summarize the biomedical applications of lignin and challenges in future perspectives. This will assist the worldwide scientific community to explore it further. Subsequently in this survey, we have reviewed the applications of lignin in drug delivery and tissue engineering comprehensively.

\section{Lignin Structural Features}

The chemical structures of lignin are complex consist of various functional groups within the molecules including phenolic, methoxy, and an aliphatic hydroxyl group. Lignin structure is as shown below in which there is ether or ester linkages with hemicellulose which is also associated with cellulose. . $^{1920}$ Figure 2 presents the structure of lignocellulosic biomass with major components. ${ }^{19}$ The pure form of natural lignin is colorless, however, its color changes to brown or dark brown after acid or alkali treatment. The properties of lignin rely on these functional groups and the most abundant hydroxyl group in lignin is the aliphatic hydroxyl group. Different sources of lignin can have different proportions of hydroxyl groups. ${ }^{21}$ Lignin can be classified as native lignin and technical lignin. Original lignin structure without any modification is called native lignin whereas lignin extracted from industrial by-product is known as technical lignin. Technical lignin can be of different types depending upon the sources and extraction methods. ${ }^{20}$ Lignin acts as a binder to assemble the plant cell walls by associating with the cellulose and hemicellulose in the plant cell. ${ }^{3,19,22-24}$ Figure 3 presents the lignin, cellulose, and hemicellulose units in biomass. ${ }^{20}$ This

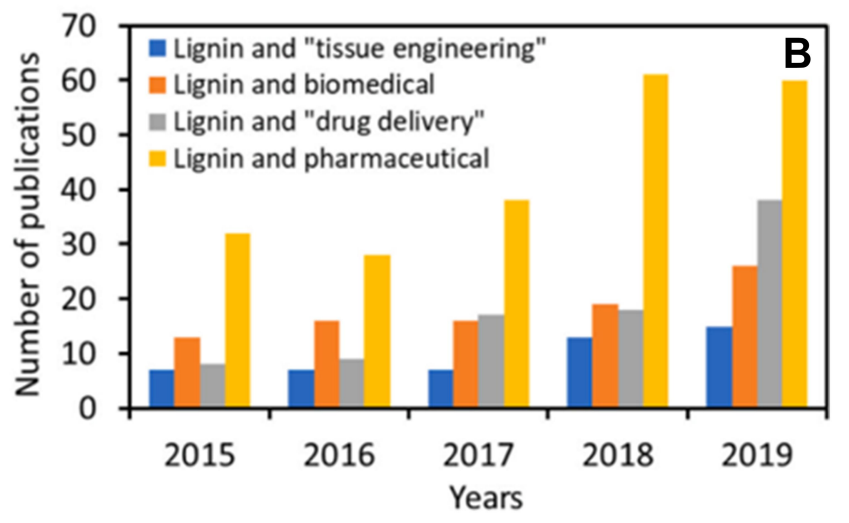

Figure I Progress of research articles about lignin (A) and its application in different fields (B). Reprinted from Sustain Chem Pharm, I8, Domínguez-Robles J, Cárcamo Martínez Á, Stewart SA, Donnelly RF, Larrañeta E, Borrega M. Lignin for pharmaceutical and biomedical applications - could this become a reality? I00320, Copyright (2020), with permission from Elsevier. ${ }^{14}$ 


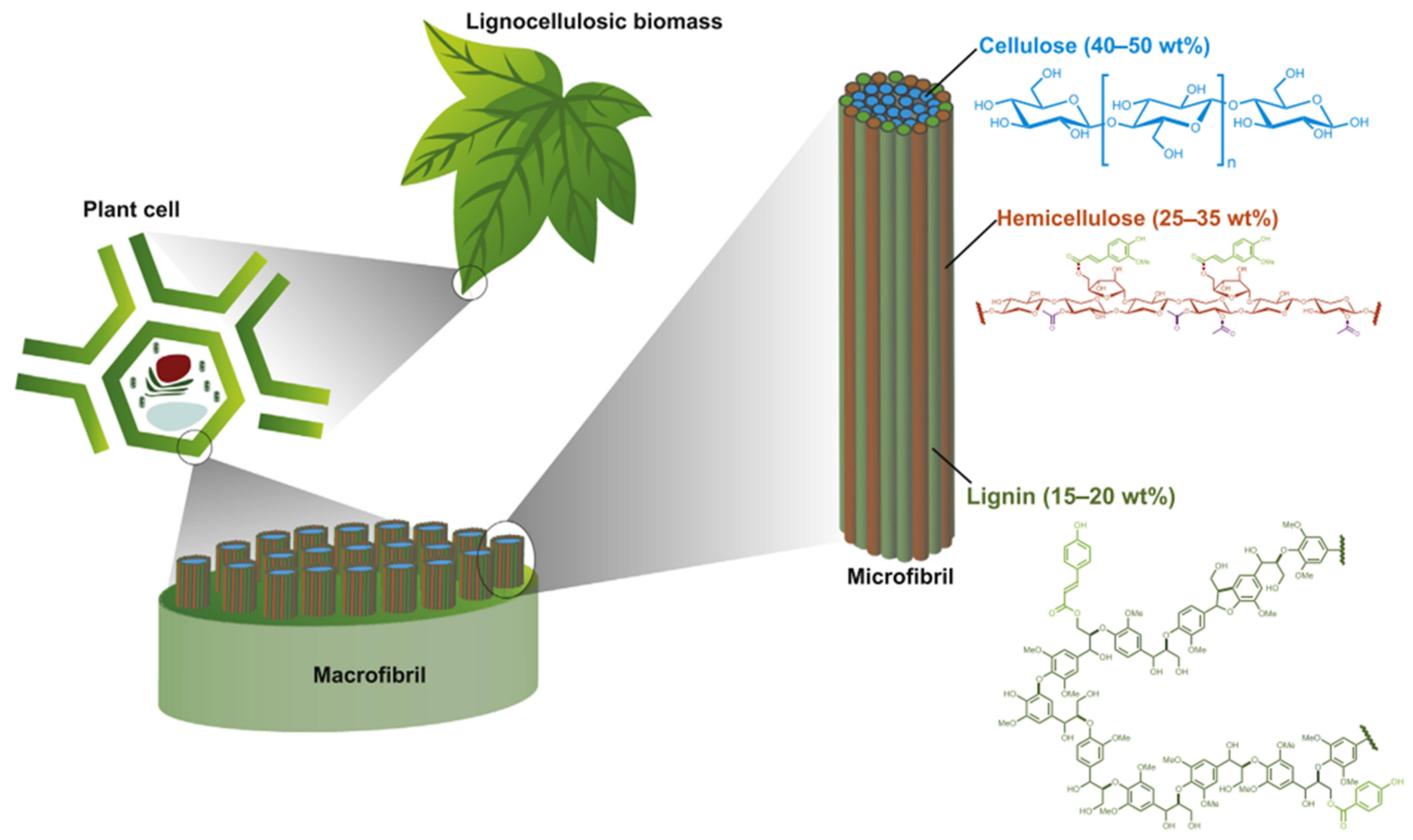

Figure 2 Systemic of lignocellulosic biomass structure and major components. Reprinted from Trends Chem. 2(5), Bertella S, Luterbacher JS. Lignin functionalization for the production of novel materials, 440-453, Copyright (2020), with permission from Elsevier . ${ }^{19}$

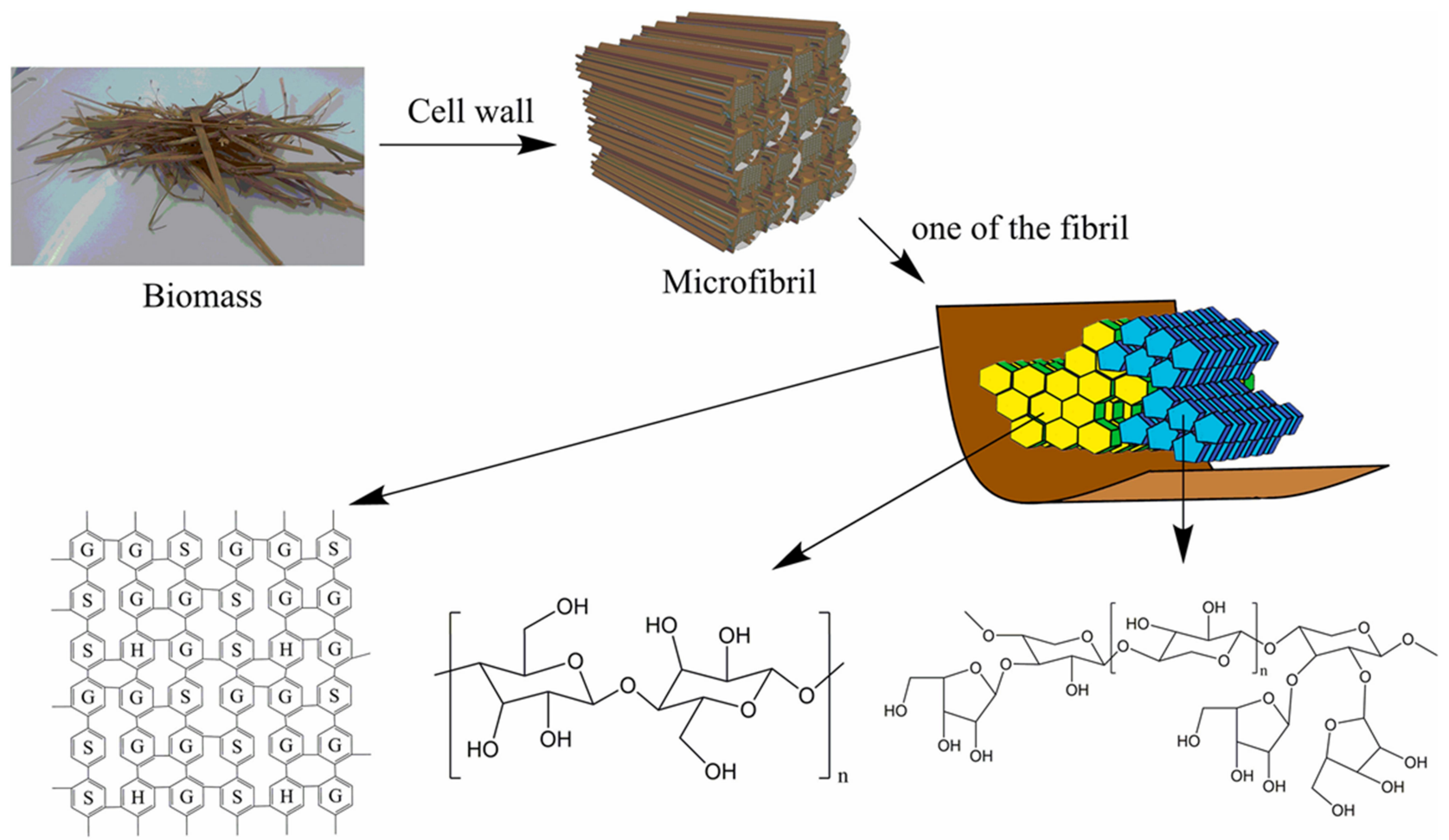

\section{Lignin}

Cellulose

Hemicellulose

Figure 3 Lignin, cellulose, and hemicellulose units in biomass. Reprinted from Renew Sustain Energy Rev, I07, Chio C, Sain M, Qin W. Lignin utilization: a review of lignin depolymerization from various aspects, 232-249, Copyright (2019), with permission from Elsevier. ${ }^{20}$ 
phenomenon provides mechanical strength to the plant cell wall and also regulates the water conduction as well as protecting other components from enzymatic degradation. ${ }^{3}$ Therefore, lignin can be termed as a "building element" in the design of biomaterials (eg lignin-based materials, epoxy, or polyurethane). ${ }^{25}$ It has resistant to most of the biological attacks in comparison to hemicelluloses/cellulose. ${ }^{1}$ Moreover, the biomedical properties of the lignin-based materials also depend on their structure, type of active functional groups, molecular weight, type of lignin obtained from the plant sources, isolation methods, etc. ${ }^{2}$

The utility of lignin is suppressed in most of the applications due to insolubility in the aqueous media. ${ }^{4,7}$ One of the ways scientists have been explored to address this issue is chemical modification. $^{2,3,8}$ Lignin is associated with the many active groups/functional groups such as phenolic/alcoholic hydroxyl groups, aromatic units, carbon-carbon double bonds, etc., which enable the development of chemically modified derivatives. $^{2-8}$ Based on the literature survey, lignin can be converted into different useful materials by various methods: 1) depolymerization of lignin into the corresponding aromatic macromers for carbon source, 2) chemical modification of active functional groups, 3) creating new chemical active sites on the lignin, and 4) production of lignin graft copolymers. ${ }^{2,3}$ The presence of active functional groups in lignin enables it to undergo acetylation, alkylation, and many other chemical reactions including halogenation, reduction, nitration, oxidation, sulfonation, hydrogenation, hydrolysis, and fusion with alkalis/metals for structural modification (Figure 4). ${ }^{18,25}$ In this way, high-value-added lignin-based bio and nanomaterials can be synthesized for a variety of applications in different areas. Another possible route explored for the development of highvalue usage lignin-based materials is hybridization with the inorganic components. ${ }^{12,13,26}$ Lignin can be associated with the inorganic nanomaterials that form lignin-based hybrid nanocomposites. Hybridization changes the chemical nature and reactivity of lignin. Because of the neutral 3D network, lignin can afford the uniform lignin/inorganic nanocomposite system when it combines with the inorganic nanoparticles/metals. ${ }^{26}$ The resultant lignin-based nanomaterials can be used as highvalue-added materials for potential applications in various biomedical domains, particularly in drug/gene delivery and tissue

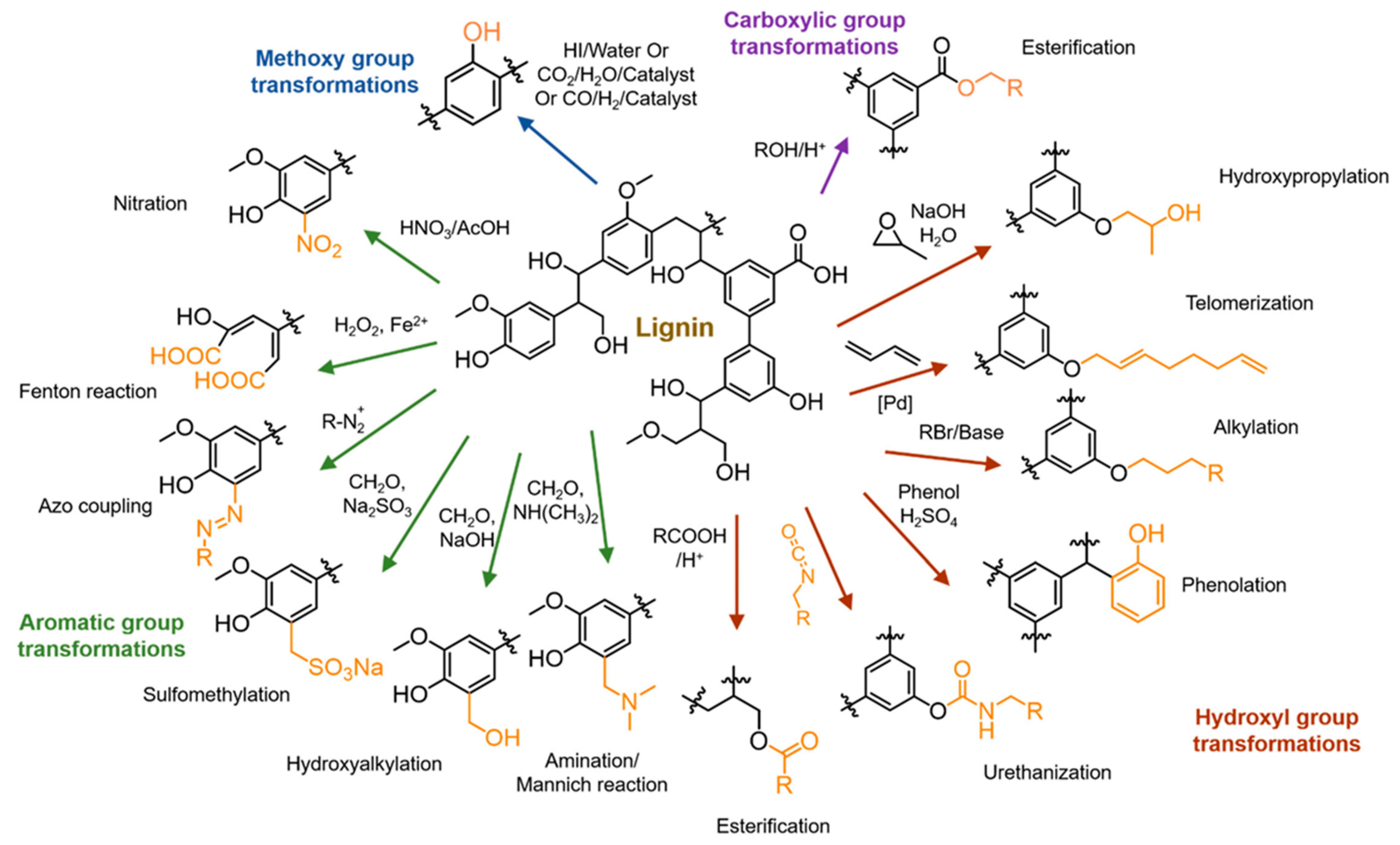

Figure 4 Chemical transformation of lignin to introduce diverse functional group. Reproduced from Ganewatta MS, Lokupitiya HN, Tang C. Lignin biopolymers in the age of controlled polymerization. Polymers (Basel). 2019;II(7):II76. Creative Commons license and disclaimer available from: http://creativecommons.org/licenses/by/4.0/ legalcode. $^{18}$ 
engineering due to synergetic interactions from both organic lignin and inorganic nanocomposites. ${ }^{12,13,26}$ The binding ability of lignin with nanomaterials or other multivalent metal ions involves active functional groups (phenol, hydroxyl, and carboxyl groups), which act as both chelating and reducing agents to the metal center. ${ }^{2,3,8}$ The chelating ability of lignin depends on the type of lignin and its chemical structure. Lignin is used as wood adhesives to improve the mechanical properties of thermoplastic polymer composites. ${ }^{12,17,27,28}$ For example, the phenol in phenol-formaldehyde resin was replaced with lignin to improve its compatibility and mechanical properties. ${ }^{12,17,27,28}$ Recently, it has been reported that the lignin nanoparticles that dispersible in the water can be used to stabilize Pickering emulsions and also used as a silver ions carrier in antimicrobial applications. $^{29-32}$ They have also been utilized successfully in drug delivery and tissue engineering applications. ${ }^{2}$

\section{Lignin in Drug Delivery}

Pharmaceutical formulations are delivered to the desired site in the body sometimes using nanoparticle-based carriers to safely achieve their desired therapeutic effects. ${ }^{33}$ Various nanoparticles have been extensively explored. Lignin-based composites are in the current trend for the purpose discussed in the introduction section. Nanoformulation is a significant procedure used to develop Lignin nanoparticles for drug delivery systems. The valorization of lignin-based nanoparticles in drug delivery, tissue engineering is being increased because of its excellent physicochemical properties including antibacterial, antioxidant, and antiparasite properties. Kinetically controlled release of drugs makes them a suitable candidate for drug delivery applications. The synthesis of lignin nanoparticles has widely been investigated. Kumar et al recently documented the wide range of lignin nanoparticle synthesis protocols. The most widely used methods are milling, highpressure homogenization, solvent shifting method, $\mathrm{pH}$ shifting method, template-based synthesis technique, ice-segregation induced self-assembly process, aerosol process, electrospinning method, supercritical fluid method, solvent antisolvent precipitation, and acoustic cavitation assisted nanoparticles preparation. ${ }^{34}$

Recently, different forms of lignin nanoparticles are being exploited based on various development strategies. Formulating nanoparticles also ameliorate the bioavailability, absorption, and solubility of various compounds to improve their therapeutic efficacy. ${ }^{35-40}$ Lignin, being the most suitable option owing to potential benefits in therapeutic drug delivery has become the choice of research in the biological and medical field. Figure 5A$\mathrm{C}$ presents the widely used strategies for the formulation of

A

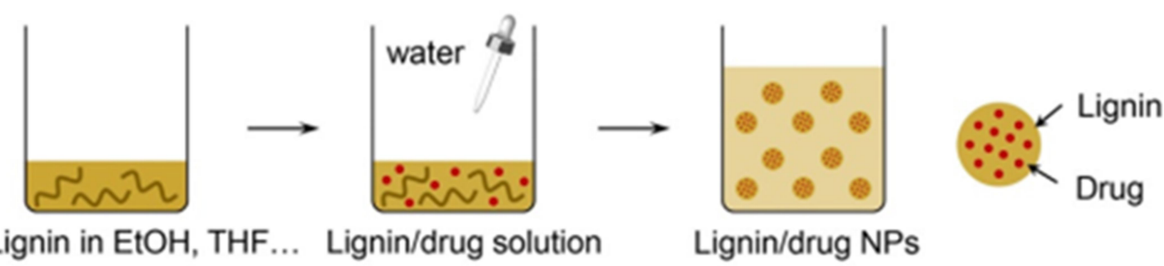

B

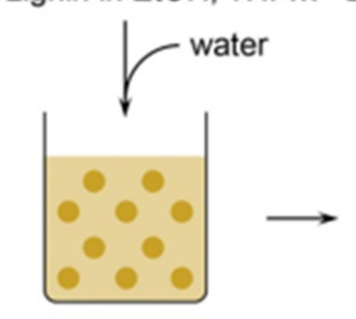

LNPS

C

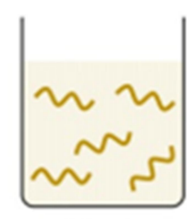

Lignin

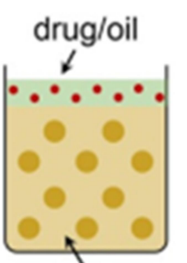

LNPs/water

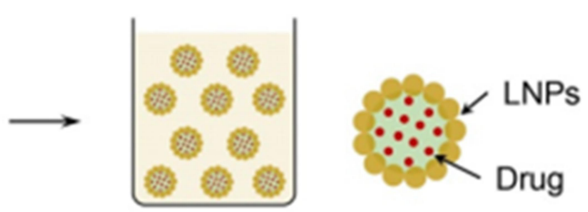

LNPS stabilized emulsion

Figure 5 Widely used strategies for formulation of different drug delivery systems-based lignin. (A) nanoparticles of lignin and drug mixture, (B) drug loaded lignin nanoparticles stabilized emulsion, and (C) lignin wraps drug into nanoparticles. Reproduced from Liu R, Dai L, Xu C, Wang K, Zheng C, Si C. Lignin-based micro- and nanomaterials and their composites in biomedical applications. ChemSusChem. 2020;13(I7):4266-4283. (C) 2020 Wiley-VCH Verlag GmbH \& Co. KGaA, Weinheim. ${ }^{2}$ 
different lignin-based drug delivery systems. ${ }^{2}$ Gilca et al synthesized lignin nanoparticles from commercially available lignin (wheat straw and Sarkanda grass) by simply ultrasonication at $20 \mathrm{kHz}$ frequency, $600 \mathrm{~W}$ power. The obtained particles were spherical and $0.01-0.05 \mu \mathrm{m}$ in size. Results showed that phenyl coumaran and pinoresinol subunits were completely degraded and aryl glycerol aryl ether subunits (b-O-4) were reduced due to this acoustic irradiation, and these were the main reasons for the size reduction of lignin. ${ }^{41}$

The major challenge in nanoparticle synthesis is the stability of nanoparticles in aqueous solutions which greatly affect their use in biomedical applications. Therefore, it is more important to understand the stability and mechanism of aggregation. Lindstromn et al reported a series of experiments on the aggregation behavior of kraft lignin in aqueous solutions and discussed the aggregation mechanism. The carboxylic groups were never in a position to form dimeric complexes, thus possible association was believed to be between the carboxylic groups and various ether oxygens and hydroxylic groups. ${ }^{42}$ The kraft lignin particles were elongated in shape, and the size was less than $10 \mathrm{~nm}$ [1-3 nm thick 5-9 nm in length]. According to this study, aggregation of kraft lignin starts with the self-association of macromolecular kraft lignin into compact colloidal particles in solutions of simple electrolytes. These particles then associated with fractal aggregates ranging in size from about $100 \mathrm{~nm}$ to $1-2 \mu \mathrm{m}$ sized nanomaterials. ${ }^{43}$ Further to understand the colloidal stability of lignin nanoparticles, Moreva et al dealt with the comprehensive studies of the colloidal chemical behavior of kraft lignin in aqueous systems in a wide range of $\mathrm{pH}$. In the alkaline $\mathrm{pH}$ range, kraft lignin mainly consisted of particles of a size smaller than $30 \mathrm{~nm}$. With a decrease in $\mathrm{pH}$, the size of kraft lignin particles sharply increased as a result of a decrease in the electrostatic constituent of the particle interaction energy. At $\mathrm{pH} 5$ and 4 , the prevalent particle size was 50-100 (57 wt \%) and 150-200 nm (74 wt \%), respectively. In the isoelectric point of kraft lignin (pH 2), the prevalent particle size reached several micrometers: $38 \mathrm{wt} \%$ from 1000 to $1500 \mathrm{~nm}, 15 \mathrm{wt} \%$ from 1500 to $2500 \mathrm{~nm}$, and $27 \mathrm{wt} \%$ larger than $3500 \mathrm{~nm}^{44}$

At the same time, it is more important to understand the formation of nanoparticles of lignin. Several researchers investigated the mechanism of lignin nanoparticle formation. According to their proposed mechanism, lignin self-assembly in an aqueous ethanol solution involves a nucleation growth process. Nucleation is initiated by the precipitation of large lignin fragments. The growth takes place through collision-driven aggregation and fusing of the particles. There are different parameter affect the physicochemical properties of lignin nanoparticles such as lignin concentration, dilution rate, the nonsolvent effect on lignin nanoparticles properties, and molecular weight fractionation. ${ }^{45}$ Rangana and his group demonstrated the site-specific breakdown of the lignocellulosic complex structure of Luffa cylindrica by MultifectCX GC Cellulase, Multifect Pectinase FE, Optimase CX 255L enzymes to yield uniform cuboidal lignin-rich nanoparticles (size 20-100 nm). Results showed that the cellulosic content in nanoparticles was substantially reduced, and the degradation mainly occurred at the polymeric linkage sites ie, at glycosidic linkage. Moreover, the hydrogen bond and inter/intra- molecular interactions were also weakened upon enzymatic treatment. The remaining mass after enzyme digestion of Luffacylindrica was mainly lignin which showed strong absorbance at $278 \mathrm{~nm}$ in the UVVis spectrum of the enzyme-treated sample. ${ }^{46}$ The morphology of nanoparticles is another major crucial factor, plays a role in drug delivery, and it is challenging to prepare the morphology-controlled nanoparticles. ${ }^{47}$ Yiamsawas et al prepared a morphology-controlled formulation of lignin nanoparticles such as solid nanoparticles, core-shell nanoparticles, and porous nanoparticles. ${ }^{48}$ Moreover, several methods limit the capability to prepare the nanoparticles of lignin below $100 \mathrm{~nm}$. To overcome these limitations, Nair et al introduced a new method to prepare nano lignin using a shear homogenizer (IKA Ultra-Turrax T-50 Homogenizer) operated at 15,000 rpm for $4 \mathrm{~h}$. The obtained nanoparticles were less than $100 \mathrm{~nm}$ in size; although, there were no major changes on the core lignin structures (no apparent cleavage of aryl-O-ether linkages) after mechanical treatment. These nanoparticles were mixed with aqueous PVA solution $(10 \% \mathrm{w} / \mathrm{w})$ by simple manual stirring, without using any crosslinker. It was reported that the thermal stability of PVA was improved with the incorporation of homogenized nano lignin. $^{49}$

The nanoparticulate system such as nanoparticles, nanospheres, nanocapsule, nanoemulsion, hydrogel, and micelles are widely studied. Lignin nanoparticles are a promising tool for biodegradable drug delivery. Lignin nanoparticles have acquired focus in the last decade because of their potential utility in drug delivery. Ligninbased nanocarrier systems (Figure 5A-C) are the most promising systems into which drugs can be embedded or dispersed as particles. Lignin can generate nanoparticles 
for the encapsulation of various therapeutics for many pharmaceutical applications including anticancer treatment. ${ }^{12}$ Frangville et al explored nontoxic lignin nanoparticles for the entrapment of Rhodamine $6 \mathrm{G}$ with high drug loading capacity. ${ }^{13}$ Alqahtani et al have prepared lignin nanoparticle-based oral formulation for the effective delivery of curcumin. The prepared lignin nanoparticle exhibited good stability under acidic conditions and demonstrated a sustained release in the simulated intestinal fluid. Also, their study suggested that nanoparticles could enhance the permeability of curcumin and reduced the P-glycoprotein (P-gP) mediated efflux. The half-life and bioavailability of the lignin-based curcumin nanoparticles were found higher than that of suspension upon oral administration. ${ }^{50}$ Lignin is also used as a carrier for gene delivery. Liu et al developed a lignin-based graft copolymer as a promising non-viral gene vector. They had chosen the atom transfer radical polymerization (ATRP) method for the co-polymerization of lignin-based macroinitiators (esterified lignin) with 2-(dimethylamino) ethyl methacrylate. Cationic amphiphilic lignin-based graft copolymers were formed which had a hyper-branched structure with a hydrophobic backbone of lignin and multiple cationic hydrophilic arms of poly (2-dimethylaminoethyl methacrylate). Figure $6 \mathrm{~A}$ presents the synthesis of the ligninPDMAEMA graft copolymer (LnPDMAEMA) via ATRP. ${ }^{51}$ This cationic lignin-based graft copolymer was efficiently condensed with negatively charged plasmid DNA (pDNA) and formed nanoparticles of size 100 to $200 \mathrm{~nm}$. These nanoparticles showed good gene transfection efficiency in cell lines of Cos-7 (Figure 6B), Hela (Figure 6C), and MDA-MB-231 (Figure 6D). ${ }^{51}$

Among very few targeted cancer therapies, MEK1/2 inhibitor GDC-0623 was used in Phase 1 clinical trials on patients having advanced solid tumors. However, those clinical trials were failed, because of either poor solubility of inhibitor in water or lower blood circulation time, and lack of tissue penetrations. Nanotechnology-based approaches have a proven record to overcome such limitations through different drug delivery systems such as nanoformulation, ${ }^{52}$ solid lipid nanoparticles, ${ }^{53}$ and polymer-based drug delivery approach. ${ }^{54}$ Among polymer-based drug delivery systems, poly(lactic-co-glycolic acid), PLGA based is one of the promising and FDA-approved delivery vehicles. ${ }^{55}$ Byrne et al
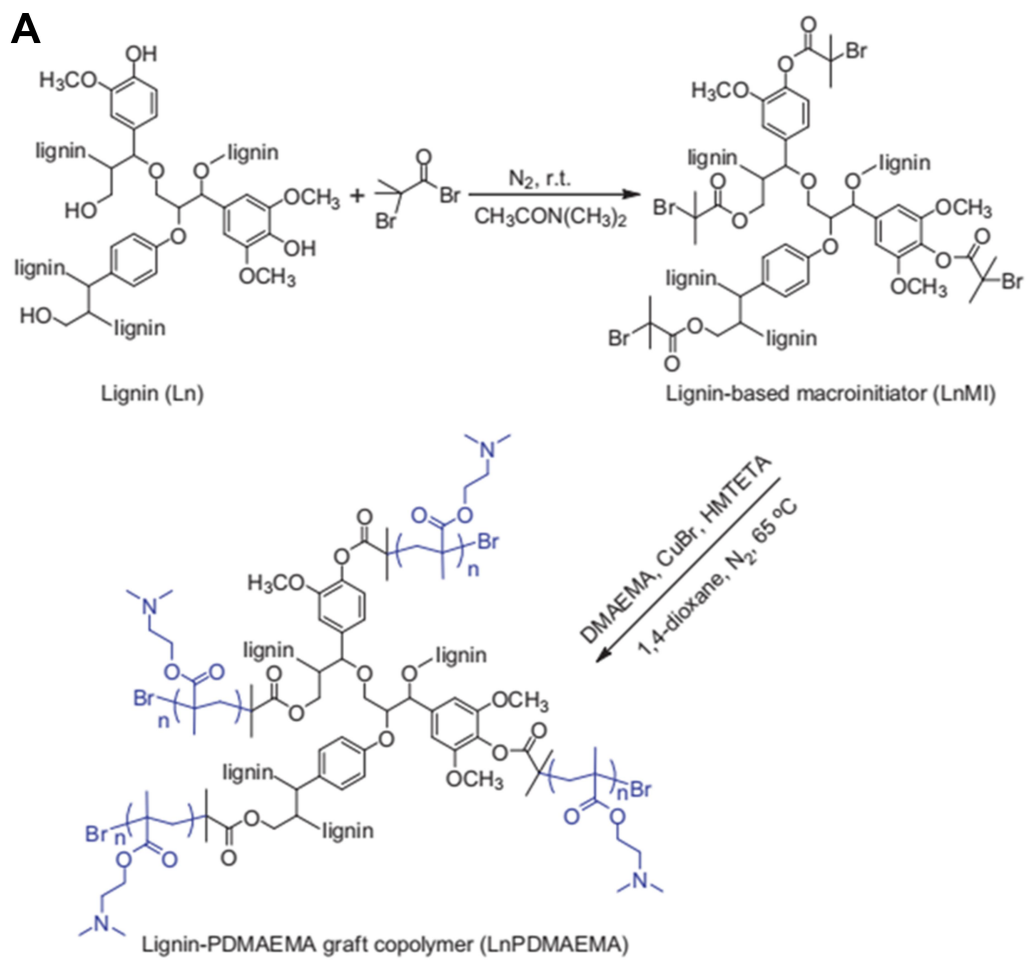

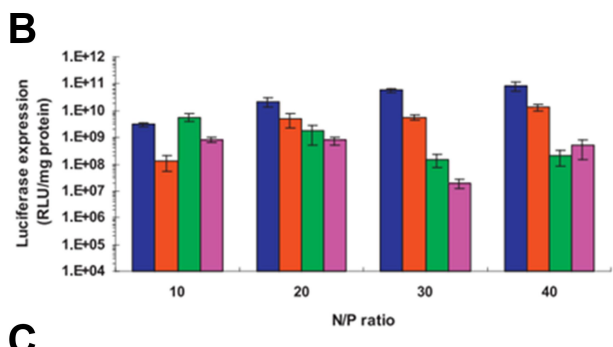

C
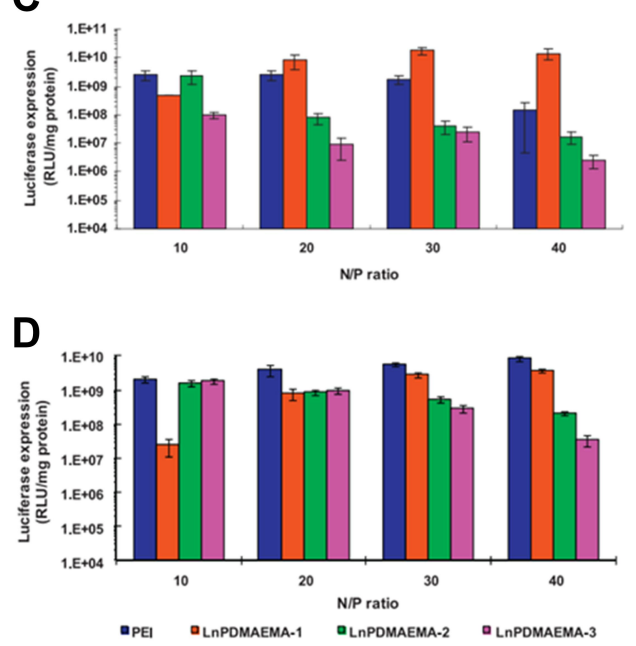

Figure 6 (A) lignin based micro initiator and graft copolymer LnPDMAEMA synthesis through ATRP. Graft copolymer transfection efficiency in different cell lines Cos-7 (B), MDA-MB-23I (C), and HeLa (D) cells. Reprinted from Colloids Surf B Biointerfaces, I25, Liu X, Yin H, Zhang Z, Diao B, Li J. Functionalization of lignin through ATRP grafting of poly(2-dimethylaminoethyl methacrylate) for gene delivery, :230-237, Copyright 20I5, with permission from Elsevier. ${ }^{51}$ 
investigated the performance of MEK1/2 inhibitor against triple-negative breast cancer cell line through the formulation of a combined system, composed of biopolymer lignin and PLGA. They concluded that the lignin graft PLGA nanoparticles are superior delivery vehicles to deliver GDC-0623 to cancer cells with enhanced efficacy in vitro. ${ }^{56}$ Another interesting strategy to make lignin nanoparticles as stimuliresponsive nanocarriers is the introduction of functional groups. Lignin was easily functionalized into carboxy lignin, which has opened a demand-based opportunity in drug delivery. Figueiredo et al developed a $\mathrm{pH}$-responsive drug delivery system for targeted delivery of anticancer drugs through post-functionalization of carboxy lignin with polyethylene glycol (PEG), and poly(histidine). The formulated nanocarriers showed low cytotoxicity and antiproliferative effect in different cancer cell lines w.r.t. normal endothelial cells as a control. $^{57}$

Magnetic nanocarriers are playing an important role in drug delivery because of several advantages such as targeted delivery, controlling the site of action, and maintain the therapeutic concentration of drugs. In past decades, tremendous progress has been made in the development of magnetic delivery vehicles. To understand the effect of lignin nanoparticles on cancer drug delivery in combination with metal nanocarriers, Figueiredo et al have formulated three different types of nanoparticles as pure lignin nanoparticles, iron (III)-complexed lignin nanoparticles (Fe-LNPs), and $\mathrm{Fe}_{3} \mathrm{O}_{4}$-infused lignin nanoparticles $\left(\mathrm{Fe}_{3} \mathrm{O}_{4}\right.$-LNPs). A poorly water-soluble drug sorafenib and benzazulene were loaded to the nanocarriers with different concentrations, showed enhanced release profile and antiproliferation effect against different cell lines. Subsequently, It could be reasoned that the superparamagnetic behavior of $\mathrm{Fe}_{3} \mathrm{O}_{4}$-LNPs is promising in drug delivery against cancer. ${ }^{12}$ Recently, Zhou et al have prepared hollow lignin nanoparticles and filled the cavity with magnetic nanoparticles and folic acid as a targeting ligand through layer-by-layer self-assembly process for the delivery of doxorubicin hydrochloride. Folic acid-metal lignin hollow nanoparticles (FA-MLHNPs) showed improved cellular uptake of drugs in HeLa cells. Further, studies are needed before proceeding for clinical trials. ${ }^{58}$

Recently, many attempts have been made to develop lignin-based nanospheres and nanocapsules. Lignin nanospheres can be fabricated through a self-assembly strategy based on the $\pi-\pi$ stackings. By escalating initial lignin concentration, more lignin molecules can participate in the production of the nanospheres, results to increase in the size of the nanosphere.
Chen et al synthesized lignin functionalized phenolic resin nanosphere using hydrothermal curing approach, also employed to prepare silver nanoparticles. Their work demonstrated the multifaceted role of lignin as a surfactant, template, and therefore, offers a novel frontier in the progress of ligninbased polymeric nanomaterials emphasizing the synergistic outcome of lignin. ${ }^{59}$ Yan et al investigated a simplistic selfassembly process to fabricate long-term stable lignin fractionation-based hollow and solid nanosphere. The results have revealed that the interaction between hydroxyl phenolic groups and the intermolecular $\pi-\pi$ plays a determining role in nanospheres production. This study provided an extensive possibility for the utilization of black liquor. ${ }^{60}$

Nanocapsule is a vesicular system having a polymeric shell, comprising an inner core that contains active ingredients. By tuning the shell material, composition, functionalization of the shell with the ligand, and stimuli, targeted drug delivery can be achieved. Compare to simple nanoparticles, core-shell nanoparticles or nanocapsules have an interesting application due to the combination of properties of core and shell materials. ${ }^{61}$ The combination of different properties and multi-functionality allows the researcher to achieve site-specific drug delivery and minimize the side effects. Recently, Kumar et al documented the various types of core-shell nanoparticle systems and their application in the diverse field. ${ }^{62}$ Lignin microcapsules and nanocapsules were also formulated by the various researcher through the oil in water emulsion, ultrasound-assisted cross-linking of lignin in the water/oil interface. ${ }^{63}$ Chen et al described the technique for the production of $\mathrm{pH}$-sensitive lignin nanocapsules based on interfacial mini emulsion polymerization. Initially, lignin was grafted with allyl groups via etherification followed by the dispersion into an oil-in-water emulsion using ultrasonication leads to the cross-linkage at the interface to form nanocapsules. The prepared nanocapsules have shown controlled release behavior and excellent drug loading capacity for coumarin- 6 and release upon changing the $\mathrm{pH}$ value of the solution, because of the presence of acidresistant groups in the shell of the capsule. ${ }^{64}$ Mika H. Sipponen and other researchers tried to formulate a hybrid nanocapsule from lignin and fatty acid using aqueous coprecipitation to explore the applicability of phase change material in the wet and dry state. ${ }^{65}$

The natural amphiphilic behavior of lignin heads is promising in formulating emulsion. For this purpose, Wei et al illustrated lignin as a colloidal molecule, which could stabilize styrene-in-water as a Pickering emulsion. LNPs 
are formulated by self-association of lignin in acidic conditions with vigorous shaking that adjoins the styrene droplets to make a Pickering emulsion. ${ }^{66}$ Sipponen et al described a newer technique for the manufacturing of cationic lignin nanoparticles (CLNPs) based on the adsorption of cationic lignin at lignin colloids. The particles demonstrated more stabilizing efficacy for Pickering emulsions to lignin colloids at $\mathrm{pH}$ values of 2-6 without positive charge ${ }^{67,68}$ Moreover, this Pickering emulsion proffers attractive to use in drug delivery owing to its several advantages that may include higher stability and entrapment efficiency and holds more resistance for coalescence than traditional emulsion as well as minimized side effects. Fewer studies have shown that it can be exploited further to deliver and store light-sensitive drugs also. Dai et al described thermally stable and UV-blocking Pickering emulsion for the stabilization of light-sensitive trans-resveratrol ${ }^{69}$ that keeps palm oil droplets in an aqueous phase by grafted lignin nanoparticles. The prepared nanoparticles showed the enhanced stability and controlled drug release profile of trans-RSV. ${ }^{69}$

Hydrogels are crosslinked polymers and can absorb substantial amounts of water to mimic the physiological tissues. Hydrogel has been used in the diverse application including hygiene, agriculture, biomedical materials and other. Due to the tunable volume in response to external stimuli, hydrogels are interesting candidates for drug delivery applications. Biopolymers such as starch, protein, gelatin, hemicellulose, lignin, cellulose, and their copolymer along with other synthetic polymers are used in the formulation of the hydrogel. Natural polymers are being used for the fabrication of hydrogels. Furthermore, renewable lignin is being studied as starting material for the preparation of hydrogels owing to its high hydrophilicity, thermal stability, and biocompatibility as well. Figure 7A-D presents the widely used strategies for the formulation of lignin-based different hydrogels. ${ }^{2}$ Also, lignin and its derivatives having a three-dimensional matrix are potential candidates for designing hydrogels. Besides, this biocompatible hydrogel was also investigated for anti-infective activity as an ointment by Mahata et al. In their study, they concluded that the co-polymerization with triazole moiety ameliorated the antibacterial and antibiofilm activity of lignin that causes downregulation of interleukins mainly IL-1 in lipopolysaccharide (LPS) induces macrophage cells and also able to reduce inducible nitric oxide synthase (iNOS) levels potentially. The study was further supported by Western blotting and NF-KB analysis assay. This novel lignin-based hydrogel has demonstrated in vivo, the capacity to prevent burn wound

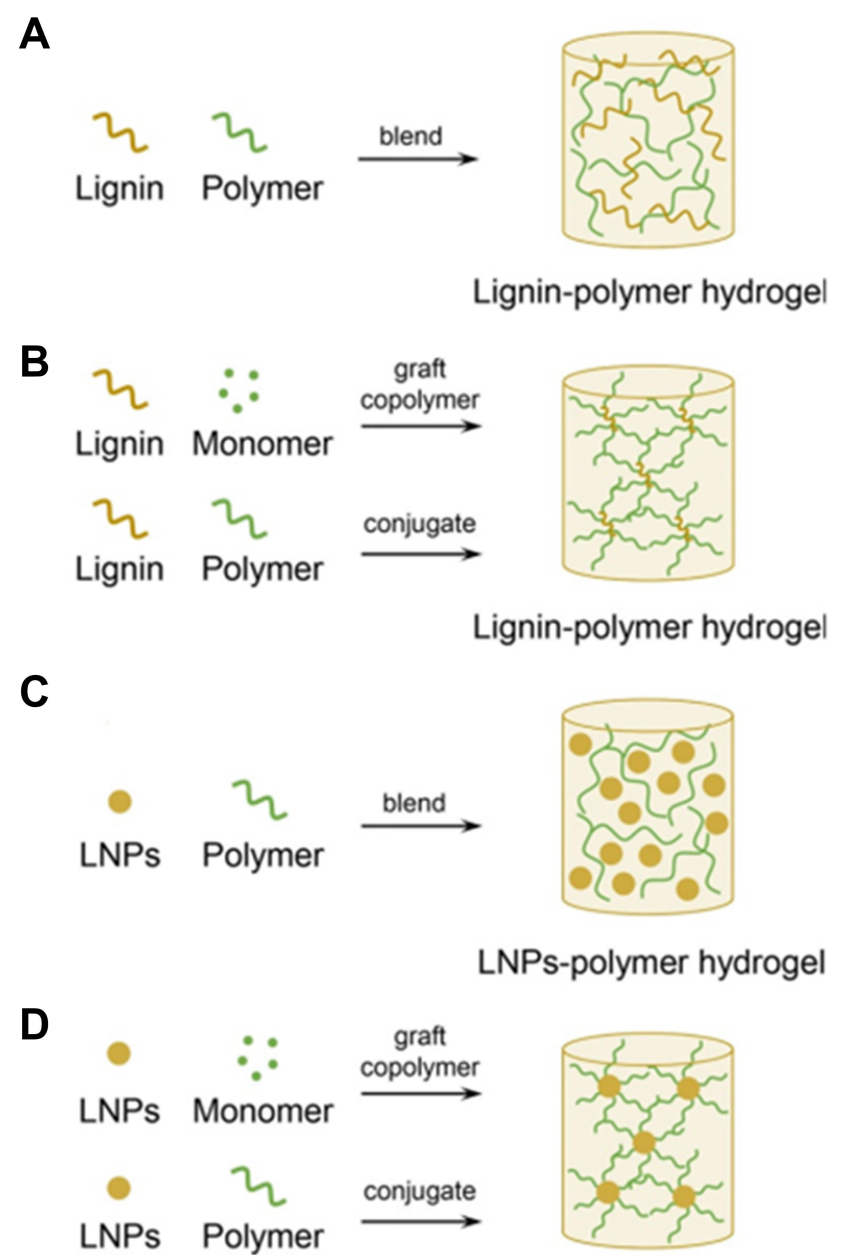

LNPs-polymer hydrogel

Figure 7 Widely used strategies to formulate lignin hydrogel. (A) lignin-polymer blend hydrogel, (B) lignin-polymer crosslinking hydrogel, (C) nanoparticles of lignin and polymer blend hydrogel, and (D) lignin nanoparticles polymer crosslinking hydrogel. Reproduced with permission from Liu R, Dai L, Xu C, Wang K, Zheng $\mathrm{C}$, Si C. Lignin-based micro- and nanomaterials and their composites in biomedical applications. ChemSusChem. 2020;13(17):4266-4283. (C) 2020 Wiley-VCH Verlag $\mathrm{GmbH} \&$ Co. KGaA, Weinheim.ref. ${ }^{2}$

infection, aid healing, and also as anti-inflammatory dressing material. ${ }^{70}$ Lignin-based hydrogel has potentially demonstrated a wide application in drug delivery. Ravishankar et al formulated a biocompatible hydrogel using chitosan and alkali lignin. The corresponding hydrogel cell viability against mesenchymal stem cells and SEM images are presented in Figure $8 \mathrm{~A}$ and $\mathrm{B}$ respectively. ${ }^{71}$ The incorporation of lignin could potentially improve the shear strength and viscosity of chitosan. The prepared hydrogel in vitro studies was found benign to mesenchymal stem cells and nontoxic to zebrafish in vivo assay at the concentration of $10 \mathrm{mg} / \mathrm{mL}$. Figure $8 \mathrm{C}$ and $\mathrm{D}$ are presenting the FDA and DAPI stained fluorescence images of cell adhesion on hydrogel, respectively. ${ }^{71}$ Further studies have revealed that the prepared hydrogels are 

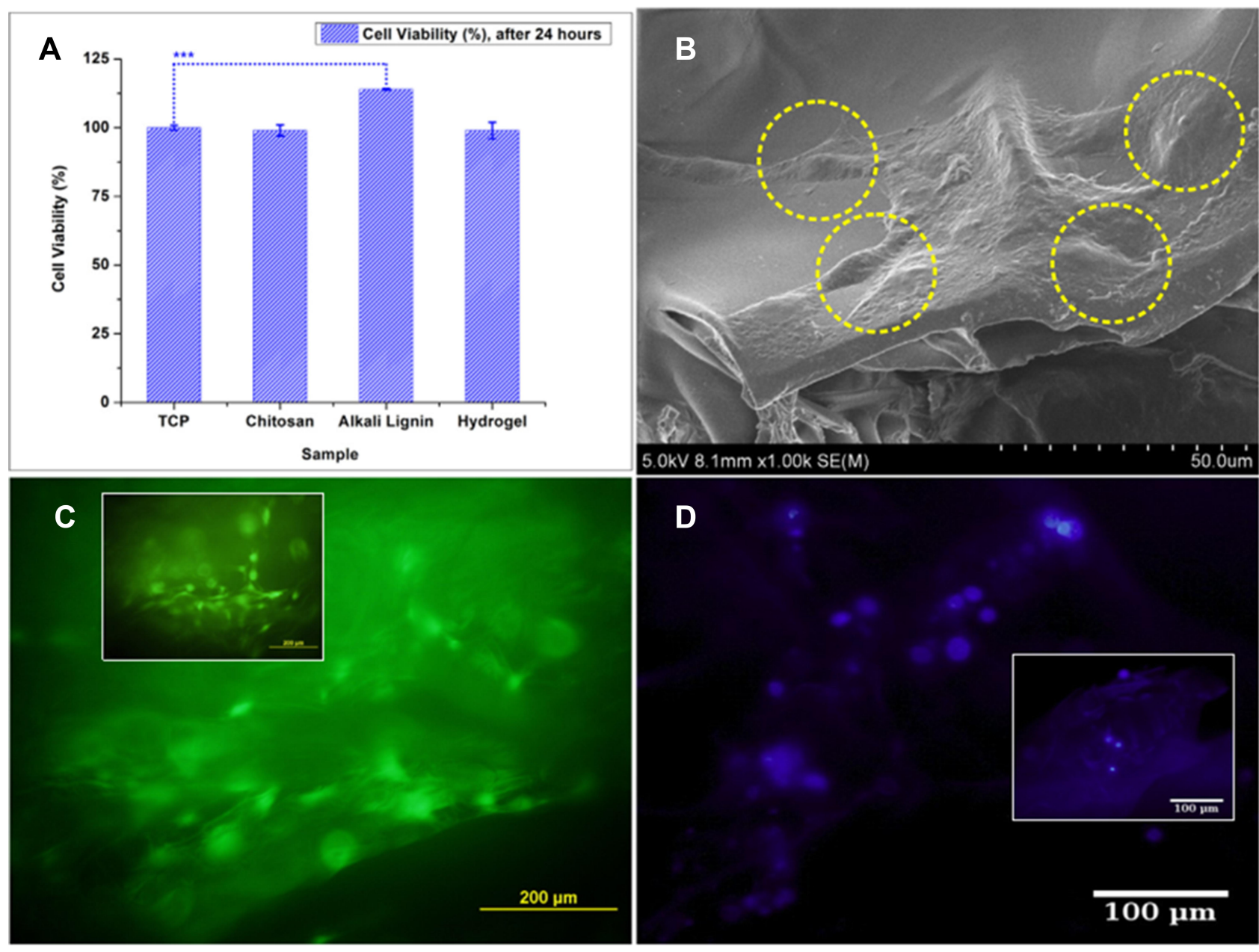

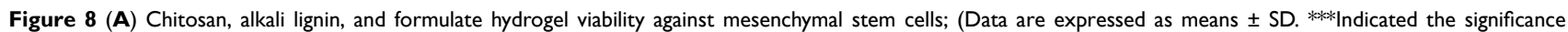
between two groups, ${ }^{* * * P}<0.00 \mathrm{I}, \mathrm{n}=3$ ); (B) SEM images (yellow dotted circles showing the cell adhesion on chitosan-alkali lignin hydrogel) and (C) FDA stain and (D) DAPI stained fluorescence images of cell adhesion on chitosan-alkali lignin hydrogel (Inset: Fluorescence micrographs showing the cell adhesion on chitosan). Reproduced from Mater Sci Eng C, 102, Ravishankar K, Venkatesan M, Desingh RP, et al. Biocompatible hydrogels of chitosan-alkali lignin for potential wound healing applications. Mater Sci Eng C, 447-457, Copyright 2019, with permission from Elsevier. ${ }^{71}$

a potential candidate for wound healing dressing materials. ${ }^{71}$ More interesting, different polysaccharides and lignin-based hydrogel were also developed for drug delivery application. Farhat et al reported the range of hydrogel using biological macromolecules starch, hemicellulose, and lignin through reactive extrusion process presence of citric acid, and SHP catalyst. The physicochemical properties confirmed their potential to use as a drug delivery system for pharmaceutical drugs. $^{72}$

Nano micelles are the nano-scaled colloidal amphiphilic monomers developed for systematic drug targeting and being employed as therapeutic carriers' systems. ${ }^{73} \mathrm{Li}$ et al employed quaternized (3-chloro-2-hydroxypropyltrimethylammonium chloride, CHMAC) alkali lignin (QAL) to formulate $\mathrm{pH}$-responsive lignin micelles loaded with ibuprofen (IBU) intended for oral delivery. ${ }^{73,74}$ The obtained micelles have demonstrated better stability in GI fluid and control over the drug release. ${ }^{73}$ Cheng et al prepared $\mathrm{pH}$ responsive lignin-based nano micelles intended for oral delivery. They exemplified in their results that the formulated micelles were $\mathrm{pH}$-sensitive and in-vitro data suggested biocompatible behavior and toxicity against HT-29 cancer cell lines. Thus, their work suggested a newer strategy for the synthesis of lignin-based nano micelles as oral delivery carrier systems. ${ }^{74}$ Lignin has been explored for its application in various drug delivery systems which has been summarized in Table 1.

\section{Lignin in Tissue Engineering}

Tissue engineering is an interdisciplinary area that includes the design and development of biomaterials, bioactive molecules, and cell combinations, and their further in-vitro and in-vivo 
Table I Lignin and Its Applications in Various Drug Delivery Systems

\begin{tabular}{|c|c|c|c|c|c|}
\hline S. No. & $\begin{array}{l}\text { Type of Lignin } \\
\text { Material }\end{array}$ & Carrier Form & Active Substance & Application & Ref. \\
\hline 1 & Alkali lignin & Nanoparticles & Trans-Resveratrol & Anticancer & [66] \\
\hline 2 & Softwood Kraft lignin & Nanoparticles & Benzazulene/sorafenib & Anticancer & {$[12]$} \\
\hline 3 & Alkali lignin & Nanoparticles & Silver nanoparticles & $\begin{array}{l}\text { Antibacterial } \\
\text { Antifungal } \\
\text { Antioxidant }\end{array}$ & [75] \\
\hline 4 & Kraft lignin & Nanoparticles & Silver nanoparticles & Antioxidant & {$[31]$} \\
\hline 5 & Alkali lignin & Nanoparticles & 10-hydroxy camptothecin & Anticancer & [76] \\
\hline 6 & Organosolv-type lignin & Nanoparticles & Curcumin & Anticancer & {$[50]$} \\
\hline 7 & Carboxylated lignin & Nanoparticles & Benzazulene & Anticancer & [77] \\
\hline 8 & Soda lignin & Nanoparticles & Budesonide & Antioxidant & [45] \\
\hline 9 & Kraft lignin & Nanocapsules & Coumarin-6 & Antioxidant & [78] \\
\hline 10 & Kraft lignin & Nanoparticles & Plasmid DNA & Gene transfection & {$[51]$} \\
\hline II & Alkali lignin & Pickering emulsion & Trans-Resveratrol & Antioxidant & [66] \\
\hline 12 & Alkali lignin & Self-nanoemulsion & Trans-Resveratrol & Antioxidant & [79] \\
\hline 13 & Alkali lignin & Nano micelles & Ibuprofen & Anti-inflammatory & [73] \\
\hline 14 & Commercial lignin & Hydrogel & Curcumin & Anti-inflammatory & [80] \\
\hline 15 & $\begin{array}{l}\text { Lignin model } \\
\text { compound }\end{array}$ & Hydrogel & $\begin{array}{l}\text { Dehydrogenative polymer of coniferyl } \\
\text { alcohol }\end{array}$ & Antioxidant & {$[81]$} \\
\hline 16 & Lignin & Nanoparticles & Rhodamine & $\begin{array}{l}\text { Encapsulation of hydrophilic } \\
\text { substance }\end{array}$ & [13] \\
\hline 17 & Lignin & Nanoparticles & Quercetin & Antioxidant & [82] \\
\hline 18 & Lignin & Nanoparticles & Doxorubicin & Anticancer & [58] \\
\hline 19 & Alkaline Lignin & $\begin{array}{l}\text { Polymeric } \\
\text { Nanoparticles }\end{array}$ & Folic acid & Anticancer & [83] \\
\hline 20 & Lignin & Nanoparticles & Resiquimod/vinblastin & Anticancer & [84] \\
\hline 21 & Lignosulfonate lignin & Carbon dots & Curcumin & Cancer Diagnosis & [85] \\
\hline 22 & Lignin & Nanocomposite & Paclitaxel & Anticancer & [86] \\
\hline
\end{tabular}

studies. Consistent advancement in tissue engineering technologies has permitted transplantation of entire organ or tissue, turned into a potential alternative for restoring damaged tissue or parts. To produce regenerative tissue for medical purposes, it is necessary to fabricate natural biomaterials. ${ }^{75}$ Figure 9 represents, the techniques were used to fabricate the different scaffold materials for tissue engineering. ${ }^{76}$ Biomaterials are major components, provide a suitable platform necessary for the regeneration and replacement of distorted tissue with functional tissue. ${ }^{77}$ Biomaterial scaffolds in tissue engineering application aimed to mimic the extracellular matrix, serve as a template to promote the growth and regeneration of a particular tissue. ${ }^{74}$

The use of lignin biopolymer in tissue engineering is an exciting research area, intended for regeneration, replacing, and augmenting the function of a particular tissue or organ of interest. For tissue engineering application, the potential of developing lignin into nanofibers and 


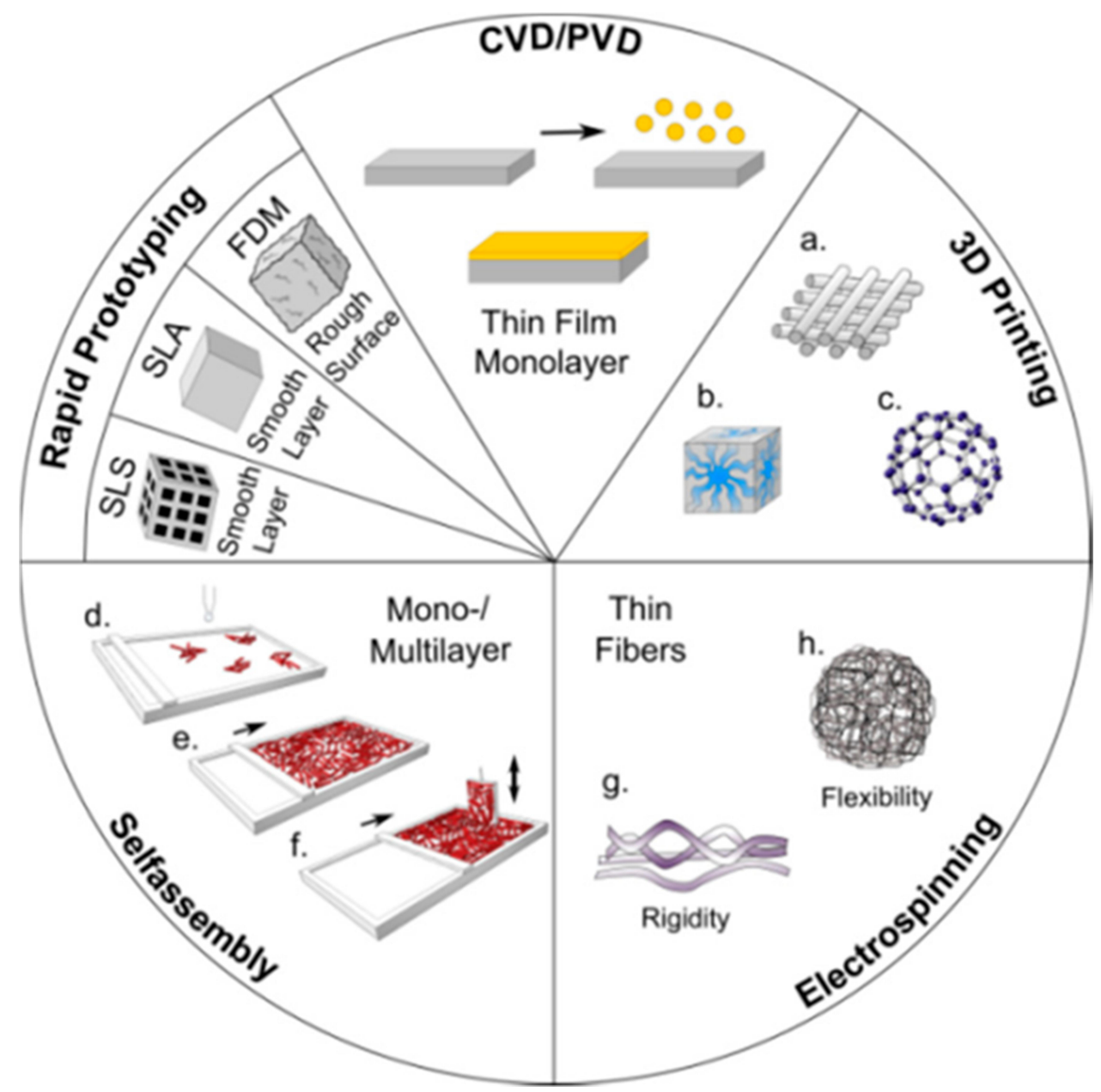

Figure 9 Strategies used for fabrication of nanoscale scaffolds for tissue engineering. Reproduced from Witzler M, Alzagameem A, Bergs M, et al. Lignin-derived biomaterials for drug release and tissue engineering. Molecules. 2018;23(8):1885. Creative Commons license and disclaimer available from: http://creativecommons.org/licenses/by/4.0/ legalcode. ${ }^{76}$

hydrogels (functional biomaterials) has been explored in recent years and the area is rapidly growing. ${ }^{17,79}$ Table 2 presents the summarized literature reports of lignin-based nanocomposites/nanofibers in tissue engineering applications. Lignin scaffolds compose of nanofibers are extensively used in tissue engineering because they mimic the chemical composition and physical structure of the native extracellular matrix. Polymeric nanofiber lignin matrix mimics the extracellular matrix due to its nanoscale size. Thus, It would be a potential candidate for developing tissue engineering scaffolds. ${ }^{3,80,81}$

Electrospun-based nanofibers with the porous and fibrous framework are another widely explored system in tissue engineering applications. ${ }^{17,82}$ Saudi et $\mathrm{al}^{83}$ fabricated aligned electrospun poly(vinyl alcohol) (Figure 10A and B), poly (vinyl alcohol) -poly(glycerol sebacate) (Figure 10C and D), and PVA-PGS fibers with different percentages of lignin such as 1 (Figure 10E and F), 3 (Figure 10G and H), and 5\% wt (Figure 10I and J) using electrospinning technique for nerve tissue engineering. ${ }^{83}$ The role of lignin on rat pheochromocytoma cells (PC12) proliferation, adhesion, and differentiation were studied. The effect of different amounts of lignin on the physicochemical properties of the fabricated fibers revealed that fibers were smooth and uniform in diameter. The modulus of elasticity and fiber diameter was increased and decreased respectively by increasing and decreasing the percentage of lignin. The results of PC12 cell culture and immunocytochemistry indicated positive effects of lignin on neural cell proliferation and differentiation. Synthetic PCL has widely been used in tissue engineering. The excellent mechanical properties and slow degradation of PCL have made this polymer demanding for nerve application, implantation, and regeneration of tissue. ${ }^{84-86}$ However, the less antioxidant activity of PCL nanofibers limits their use 
Table 2 Overview of Some Lignin-Based Nanofibers/Nanocomposites in Tissue Engineering Application

\begin{tabular}{|c|c|c|c|c|}
\hline Composition & Processing Methodology & $\begin{array}{l}\text { Potential } \\
\text { Application }\end{array}$ & Key Findings & Ref \\
\hline $\begin{array}{l}\text { Polyacrylamide (PAM)/ } \\
\text { lignin nanoparticle (LNP) } \\
\text { nanocomposite } \\
\text { hydrogel }\end{array}$ & $\begin{array}{l}\text { Ultrasonic treatment for lignin } \\
\text { nanoparticle dispersion, in-situ free } \\
\text { radical polymerization for PAM/LNP } \\
\text { hydrogel. }\end{array}$ & $\begin{array}{l}\text { Broad range of } \\
\text { application in tissue } \\
\text { engineering }\end{array}$ & $\begin{array}{l}\text { Excellent mechanical properties and } \\
\text { non-toxicity. }\end{array}$ & {$[109]$} \\
\hline $\begin{array}{l}\text { Electrospun poly ( } \varepsilon- \\
\text { caprolactone) }(\mathrm{PCL}) \text { and } \\
\mathrm{PCL} \text {-grafted lignin (PCL- } \\
\text { g-lignin) copolymer } \\
\text { nanofibers }\end{array}$ & $\begin{array}{l}\text { Ring-opening solvent free } \\
\text { polymerization. }\end{array}$ & $\begin{array}{l}\text { Osteoarthritis } \\
\text { therapy }\end{array}$ & $\begin{array}{l}\text { Excellent antioxidant activity, anti- } \\
\text { inflammatory effects, low cytotoxicity, } \\
\text { and sustained antioxidant activity. }\end{array}$ & {$[110]$} \\
\hline $\begin{array}{l}\text { Lignin-chitosan-PVA } \\
\text { hydrogels }\end{array}$ & $\begin{array}{l}\text { Mixing of aqueous-acidic solution of } \\
\text { chitosan with lignin and PVA aqueous } \\
\text { solution. }\end{array}$ & Wound healing & $\begin{array}{l}\text { The addition of lignin enhanced the } \\
\text { mechanical strength, protein adsorption } \\
\text { capacity and cell proliferation properties } \\
\text { of lignin-chitosan-PVA hydrogels }\end{array}$ & {$[\mathrm{III}]$} \\
\hline Alginate-lignin aerogels & $\begin{array}{l}\text { Exposure of alginate-lignin- calcium } \\
\text { carbonate aqueous alkali solution to } \\
\text { pressurized carbon dioxide for hydrogel } \\
\text { formation. }\end{array}$ & $\begin{array}{l}\text { Wide range of } \\
\text { tissue engineering } \\
\text { and regenerative } \\
\text { medicine } \\
\text { application }\end{array}$ & $\begin{array}{l}\text { Good cell adhesion properties without } \\
\text { compromising the cell viability. }\end{array}$ & {$[108]$} \\
\hline $\begin{array}{l}\text { PLA-lignin- poly (L-lactide) } \\
\text { composites }\end{array}$ & $\begin{array}{l}\text { Combining PLA-lignin composites with } \\
\text { poly (L-lactide) for manufacturing of } \\
\text { nanofibrous composites via } \\
\text { electrospinning process. }\end{array}$ & $\begin{array}{l}\text { Tissue engineering } \\
\text { scaffolds for locally } \\
\text { attenuating cellular } \\
\text { oxidative stress. }\end{array}$ & $\begin{array}{l}\text { Nanofibrous composites have showed } \\
\text { good biocompatibility for PCI2, human } \\
\text { dermal fibroblasts, and human } \\
\text { mesenchymal stem cells with good } \\
\text { antioxidant activity }\end{array}$ & [92] \\
\hline $\begin{array}{l}\text { Poly (vinyl alcohol) - poly } \\
\text { (glycerol sebacate-lignin } \\
\text { fibers) }\end{array}$ & Electrospinning process. & $\begin{array}{l}\text { Nerve tissue } \\
\text { engineering }\end{array}$ & $\begin{array}{l}\text { The lignin containing nanofibrous } \\
\text { composites promotes positive effects on } \\
\text { cell proliferation and neural cell } \\
\text { differentiation. }\end{array}$ & [94] \\
\hline $\begin{array}{l}\text { Lignin-poly (methyl } \\
\text { methacrylate)-poly ( } \varepsilon \text { - } \\
\text { caprolactone) }\end{array}$ & $\begin{array}{l}\text { Atom transfer radical polymerization for } \\
\text { grafting of -poly (methyl methacrylate) } \\
\text { with lignin and electrospinning process } \\
\text { for blending of this copolymer with poly } \\
\text { ( } \varepsilon \text { caprolactone) }\end{array}$ & Tissue engineering. & $\begin{array}{l}\text { Promote the proliferation and } \\
\text { interaction of human dermal fibroblasts } \\
\text { which is promising for tissue } \\
\text { engineering. }\end{array}$ & {$[104]$} \\
\hline $\begin{array}{l}\text { Lignin-poly( } \varepsilon \text {-caprolactone } \\
\text {-co-lactide)- } \\
\text { polycaprolactone, PCL and } \\
\text { poly (L-lactic acid) }\end{array}$ & $\begin{array}{l}\text { Solvent-free ring-opening polymerization } \\
\text { for lignin-poly ( } \varepsilon \text {-caprolactone-co-lactide } \\
\text { copolymer polymerization and } \\
\text { electrospinning for blending this } \\
\text { copolymer with polycaprolactone, PCL } \\
\text { and poly (L-lactic acid). }\end{array}$ & $\begin{array}{l}\text { Tissue engineering } \\
\text { and other health } \\
\text { care applications. }\end{array}$ & $\begin{array}{l}\text { Nanofibers displayed uniform and } \\
\text { beadles morphology with good } \\
\text { antioxidant activity and biocompatibility. }\end{array}$ & {$[106]$} \\
\hline
\end{tabular}

in neural tissue engineering. Several reports have revealed that incorporating lignin into PCL provides an effective

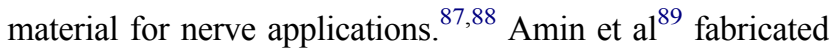
PCL fibers embedding various percentages of lignin nanoparticles by electrospinning method for peripheral nerve regeneration applications. Figure $11 \mathrm{~A}-\mathrm{D}$ showed the nerve conduit photographs in various views. ${ }^{89}$ The outcomes indicated that the length and number of neurites were increased by increasing the percentage of lignin ranging from 0 to $15 \%$. The PCL fibers made with $15 \%$ lignin nanoparticles have shown better regeneration among other scaffolds. The cell viability, differentiation of PC12 (rat phaeochromocytoma) 

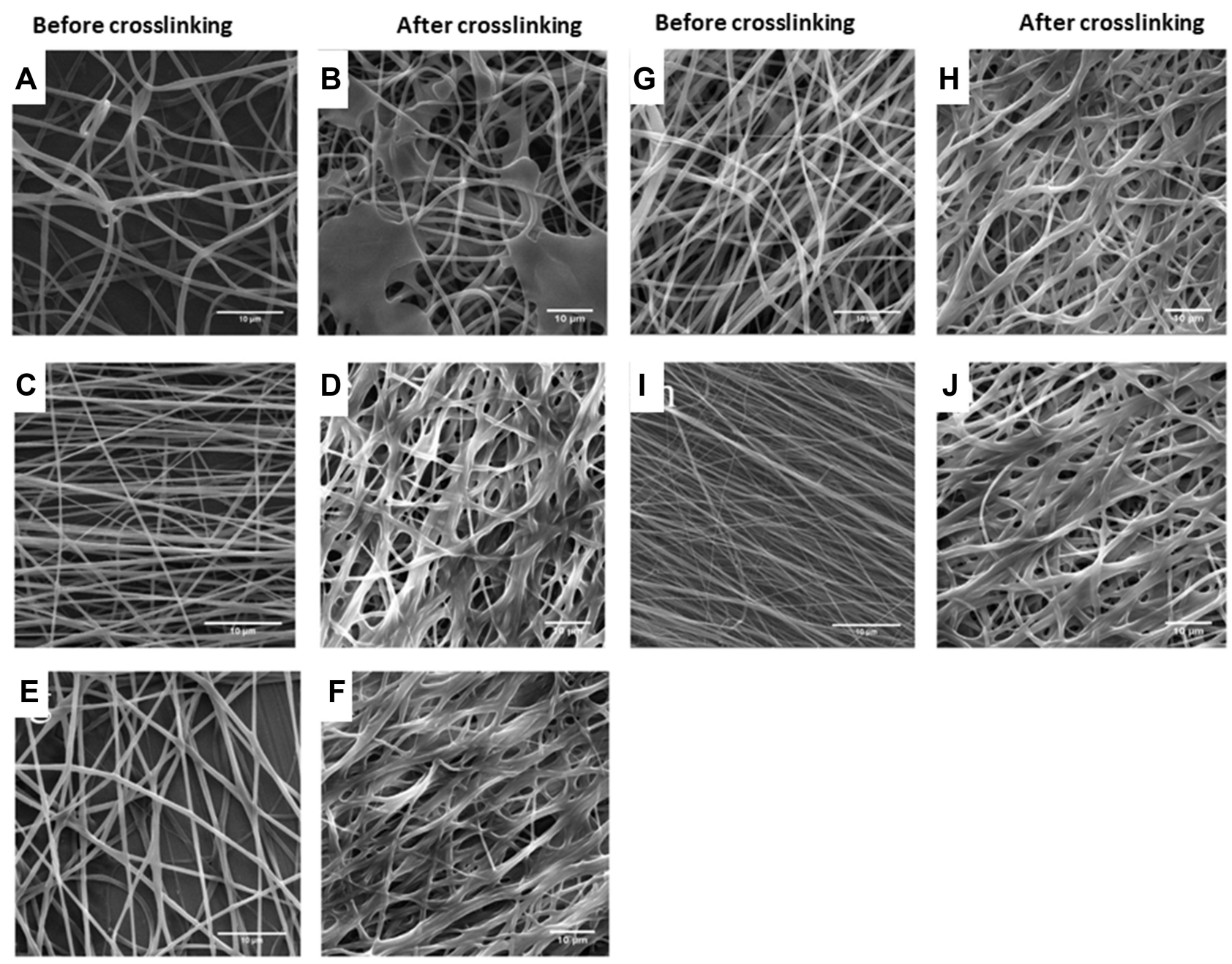

Figure 10 SEM images of crosslinked nanofibers of PVA (A and B), PVA-PGS (C and D), PVA-PGS/lignin (I\%wt) (E and F), PVA-PGS/lignin (3\%wt) (G and H), and PVA-PGS /lignin (5\%wt) (I and J) fibers. Reprinted from Mater Sci Eng C, 104, Saudi A, Amini S, Amirpour N, et al. Promoting neural cell proliferation and differentiation by incorporating lignin into electrospun poly(vinyl alcohol) and poly(glycerol sebacate) fibers, II0005, Copyright 2019, with permission from Elsevier. ${ }^{83}$

cells and human adipose-derived stem cells were prompted by increasing lignin percentage. Further, water uptake, invitro degradation, and Young's modulus were increased with increasing the lignin content. Figure 11E-H showed nerve conduit intraoperative, implantation of $\mathrm{P} 10 \mathrm{~L}$ and $\mathrm{P} 15 \mathrm{~L}$ at $10 \mathrm{~mm}$ sciatic nerve gap, and 90 days of post-surgery, respectively. ${ }^{89}$ Further investigations demonstrated that the PCL fibers embedded lignin nanoparticles are favorable for peripheral nerve regeneration, reconstruction and could be considered as a material to facilitate neurite outgrowth. ${ }^{89} \mathrm{In}$ another study, the findings of Salami et al indicated that incorporation of lignin enhanced the porosity and hydrophilic properties of the electrospun PCL/lignin nanocomposites. Moreover, lignin-based PCL nanocomposites have shown desired characteristics to mimic extracellular matrix, which can be used as a template in the design of soft tissue engineering scaffolds. ${ }^{90}$ Wang et al ${ }^{91}$ reported a function of lignin mediating the formation of human bone-like hydroxyapatite. The authors have developed a lignin-polycaprolactone fibrous matrix by employing an electrospinning process, that further induced the formation of hydroxyapatite in a simulated body fluid. The phenolic and aliphatic hydroxyl moieties present in the lignin structure are capable to provide adequate reactive sites to facilitate chelation with metal ions and subsequent nucleation and growth of hydroxyapatite via coprecipitation of calcium and phosphate ions, which is similar to the natural process of bone formation. Figure 12 presents the illustration of biomineralization of bone Hap induced by lignin. ${ }^{91}$ Furthermore, this hybrid platform of lignin biominerals provides a new prospect for lignin-based 

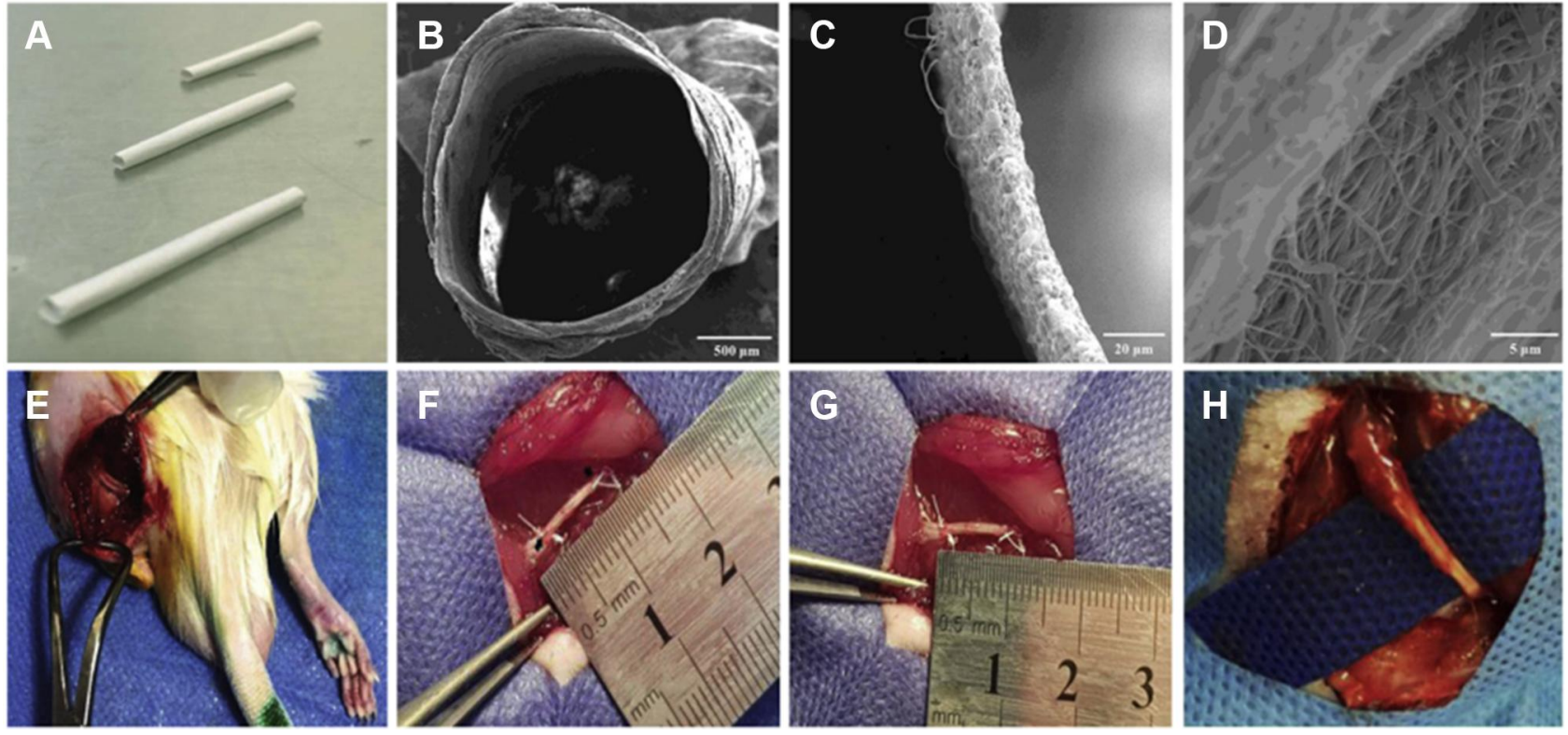

Figure I I Electrospun polycaprolactone nanofibers embedding lignin nanoparticles as nerve conduit. (A-D) different views of nerve conduit, (E) intraoperative view in the left sciatic nerve, and (F) PIOL, (G) PI5L Implantation and (H) 90 days of post-surgery at a 10 mm nerve gap. Reprinted from Int J Biol Macromol, I59, Amini S, Saudi A, Amirpour N, et al. Application of electrospun polycaprolactone fibers embedding lignin nanoparticle for peripheral nerve regeneration: in vitro and in vivo study. I54-173, Copyright 2020, with permission from Elsevier. ${ }^{89}$

Abbreviation: PIOL, PCL nanofibers with $10 \%$ wt of kraft lignin.

biomaterials in bone-related therapies and hard tissue engineering. The electrospun nanofibers made with polycaprolactone-lignin- poly (methyl methacrylate) (PCL-L-PMMA) were reported as biocompatible with reinforced mechanical properties, as the in vitro study revealed that biocompatible electrospun nanofibers were found to attach and interact well with the human dermal fibroblasts. However, the mechanism by which lignin copolymers support cell growth was not explored. $^{92}$

Lignin has been blended with other polymer matrices for various tissue engineering applications. Due to strong intramolecular and intermolecular hydrogen bond networks, lignin can manifest thermoplastic behavior in lignin-based polymeric blends and also acts as a thermoset material due to the occurrence of cross-linkages. ${ }^{93}$ Kai et a ${ }^{94}$ synthesized lignin-based copolymers lignin-poly ( $\varepsilon$-caprolactone-colactide), (PCLLA) by ring-opening polymerization. The obtained lignin PCLLA copolymers were blended with polycaprolactone and poly (L-lactic acid) to design ultrafine uniform nanofibers via electrospinning process with the ratio of lignin to PCL and PCLLA 90:10. The addition of lignin has greatly improved the mechanical properties of the nanofibers. This study concluded that good antioxidant activity, biocompatibility, and in-vitro cytocompatibility of lignin-based nanofibers, suggesting the potential for tissue engineering or biomedical application. The blending of lignin with other materials such as hydroxyapatite, calcium phosphate crystal, and polycaprolactone has been widely used for medical purposes. In situ biomineralization of hydroxyapatite on the nanofibrous surface of lignin acts as a substrate for cell proliferation and osteogenic conduction. The composite of lignin with polycaprolactone and hydroxyapatite was reported to have a good osteoconductivity for potential bone therapies. ${ }^{95,96}$

Implantation of artificial nerve grafts creates oxidative stresses, under these circumstances nerve cells would generate reactive oxygen species, which would prompt necrosis and DNA damage. ${ }^{87,97}$ The antioxidant properties of the lignin could be attractive for nerve tissue regeneration and repair. The hydroxyl and phenoxy functional groups present in the lignin biopolymer can donate hydrogens to terminate the radical propagation reaction. Owing to oxygen-free radical scavenging properties, lignin could be potentially used for stabilizing the oxygen-free radical-mediated reactions. It has been reported in the literature that a positive correlation was observed between antioxidant activity and the number of phenolic groups contained in the lignin structure. $^{87,98,99}$ Wang et al $^{100}$ synthesized ligninpolycaprolactone (PCL) and, incorporated it with PCL, and then engineered it into nanofibrous scaffolds to promote 


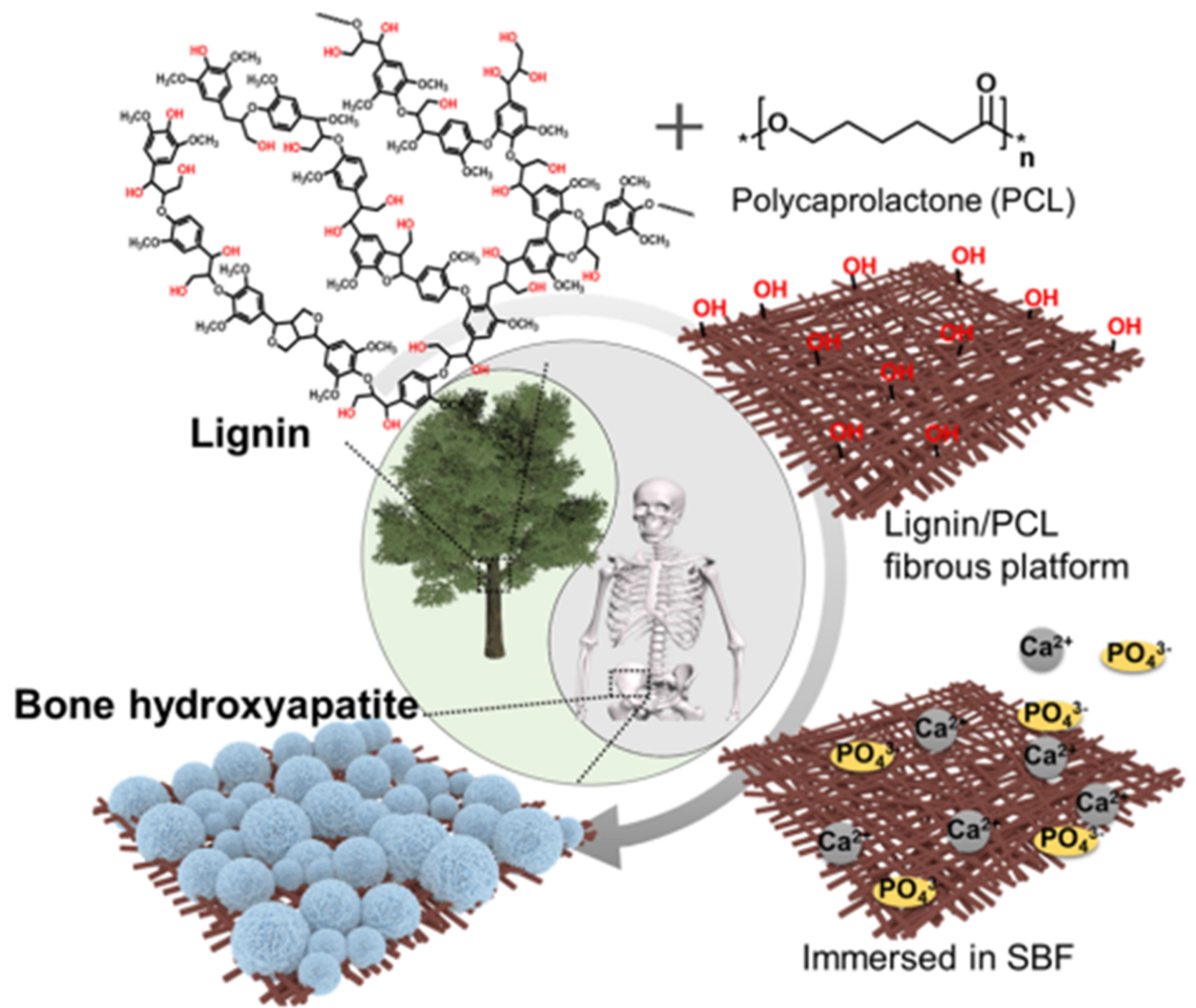

Figure 12 Systemic presentation of biomineralization of bone Hap induced by lignin. Reprinted with permission from Wang D, Jang J, Kim K, Kim J, Park CB. “Tree to bone”: lignin/polycaprolactone nanofibers for hydroxyapatite biomineralization. Biomacromolecules. 2019;20(7):2684-2693. Copyright (2019) American Chemical Society. ${ }^{91}$

neuron and Schwann cell growth. Figure 13A and B showed antioxidant activity of lignin-PCL copolymer and PCL/lignin-PCL nanofibers. ${ }^{100}$ The results demonstrated that PCL/ lignin-PCL nanofibers have the potential to preserve cells from oxidative stress effects and showed strong free radical scavenging properties. ${ }^{100}$ Moreover, myelin protein expressions of Schwann cells and stimulation of DRG neuron growth were observed with the PCL/lignin-PCL nanofibers. Figure 13C and D showed BMSCs and Schwann cell proliferation on nanofibers after hydrogen peroxide treatment. ${ }^{100}$ The findings of their studies concluded the abilities of lignin biopolymer applications for nerve and other possible tissue generation where cellular oxidative stress is a major challenge.

Lignin in combination with other biopolymers such as alginate has been used to provide a suitable environment for cell adhesion, growth, and differentiation. The alginate-lignin system may overcome the limitation of alginate including decreased protein adsorption and cell adhesion due to its hydrophilic characteristic. The presence of lignin in the alginate-lignin system lessens the hydrophilicity of alginate and presents a suitable environment required for cell attachment, growth, and differentiation. Moreover, the ultimate stability of lignin may decrease the scaffold degradation rate and helps to 

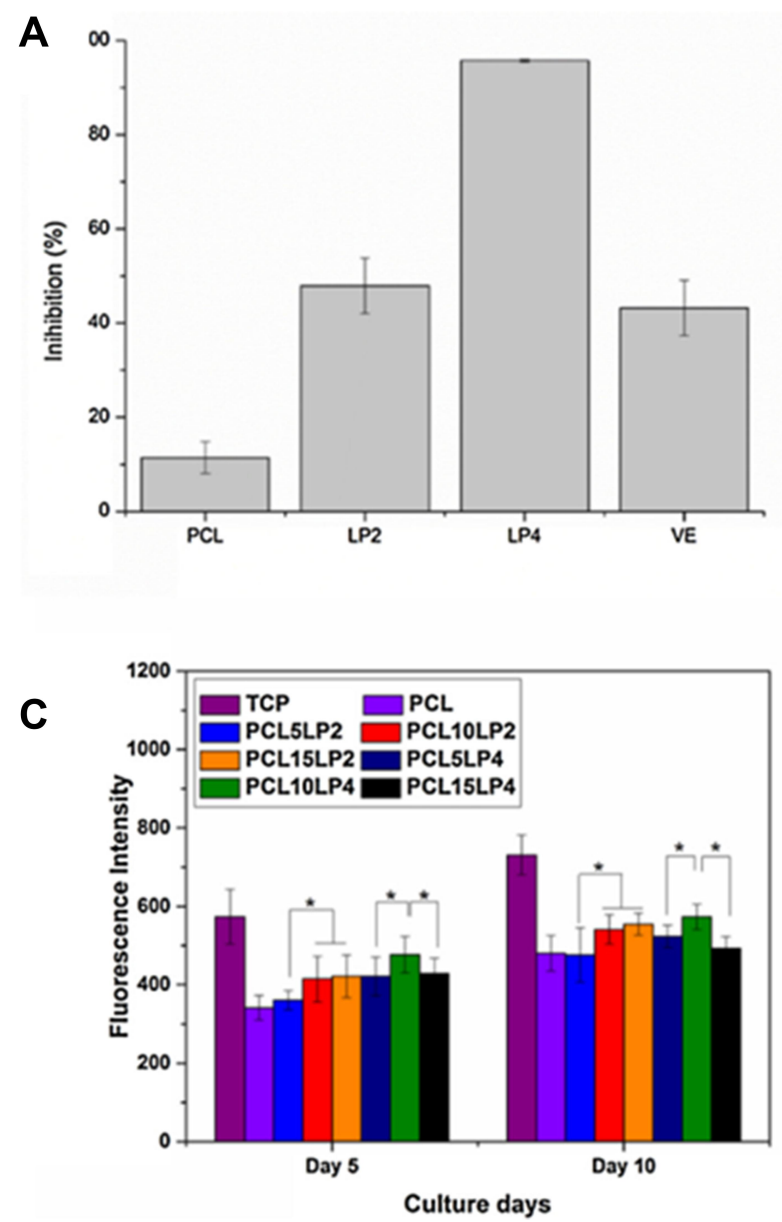
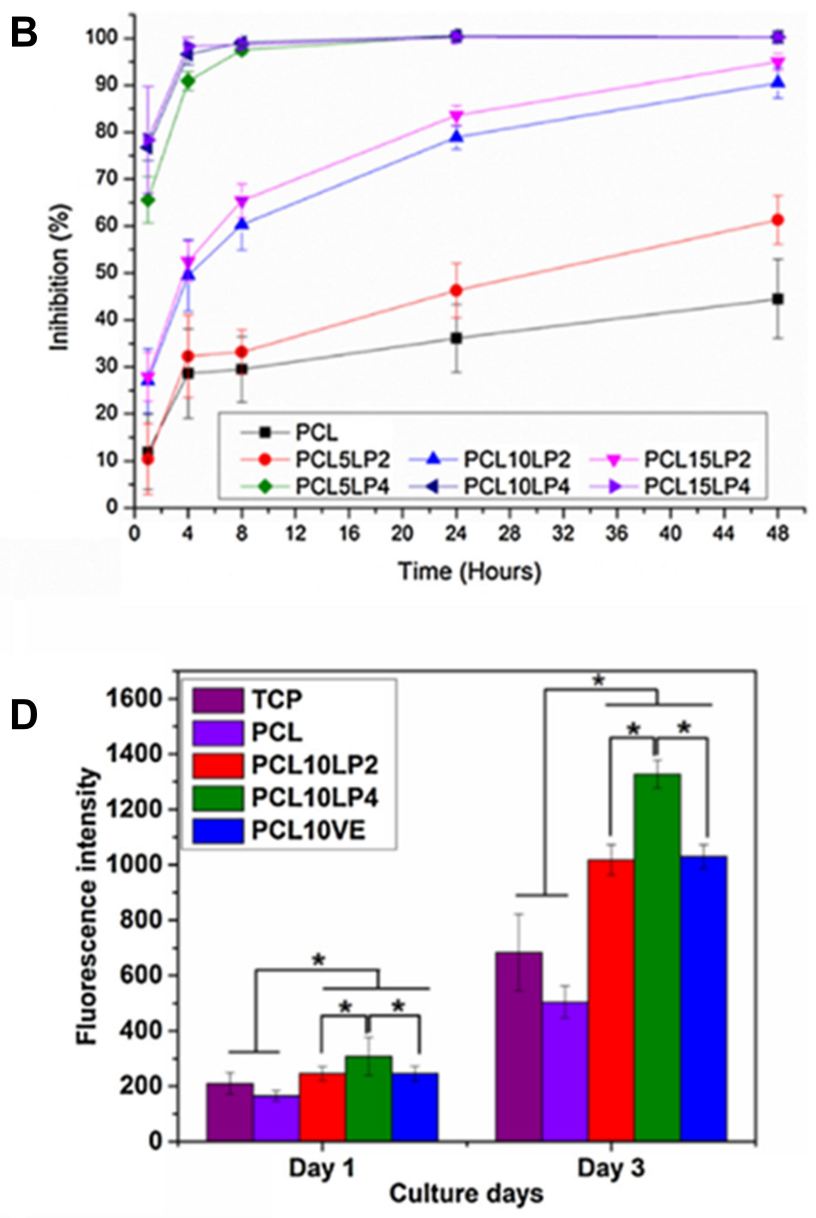

Figure 13 (A) lignin-PCL copolymer and (B) PCL/lignin-PCL nanofibers inhibition efficiency towards free radicals and proliferation of (C) BMSCs and (D) Schwann cells against nanofibers after $\mathrm{H}_{2} \mathrm{O}_{2}$ treatment. (Data are expressed as means \pm SD. *Indicated the significance between two groups, ${ }^{*} p<0.05, n=3$ ). Reprinted from Colloids Surf $B$ Biointerfaces, I69, Wang J, Tian L, Luo B, et al. Engineering PCL/lignin nanofibers as an antioxidant scaffold for the growth of neuron and schwann cell. Colloids Surf B Biointerfaces, 356-365, Copyright 20I8, with permission from Elsevier. ${ }^{100}$

Abbreviation: TCP, tissue culture plate.

match the rate of degradation with the rate of regeneration of new bone tissue. ${ }^{101,102}$ Modifying the surface of lignin nanofibers with arginine molecules led to promote reepithelialization, collagen deposition, angiogenesis, and wound closure. Figure 14 presents the microscopic images of a wound treated under different conditions at different time points. ${ }^{103}$ These effects can be explained by the argininemediated wound healing as well as the structural resemblance of lignin nanofibers to that of natural extracellular matrix proteins. Based on these properties, the arginine surfacemodified lignin nanofiber gel can be considered an effective option for the treatment of acute and chronic wounds. Moreover, the antimicrobial and antioxidant properties of lignin can potentially decrease bacterial contamination in wounds. ${ }^{103}$ Quraishi et al ${ }^{104}$ developed hybrid alginate-lignin aerogels employing pressurized carbon dioxide as an acidifier to release calcium ions for crosslinking mixture of alginate- lignin and support the gelation. The developed aerogels provide suitable textural and morphological properties with low stiffness. The cytotoxicity screening studies showed that the presence of lignin in alginate-lignin aerogels provide good cell adhesion properties without the compromise of cell viability that fulfills the requisites for regenerative medicine and tissue engineering applications. ${ }^{104}$

Owing to intrinsic structural similarity to that of the native extracellular matrix, the hydrogel platform is considered an exciting biomaterial for tissue engineering. Different types of lignin such as annual fiber crops lignin and aspen wood lignin have been incorporated with biocompatible xanthan gum-based semi-interpenetrating hydrogels. The presence of lignin in the hydrogel system could potentially enhance the swelling and thermos-oxidative stability properties. ${ }^{105}$ Chen et al ${ }^{106}$ fabricated nanocomposite hydrogels by employing lignin nanoparticles (cross-linking 

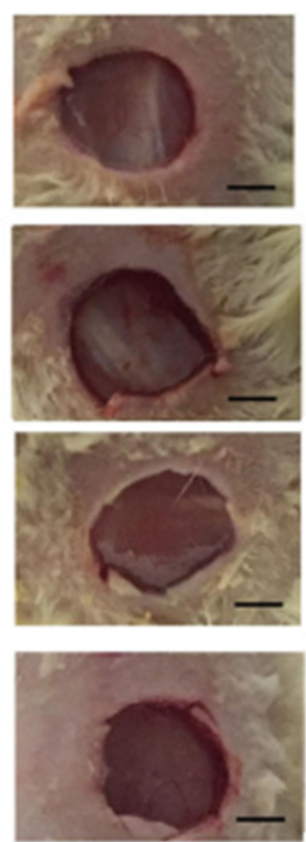

Day 0
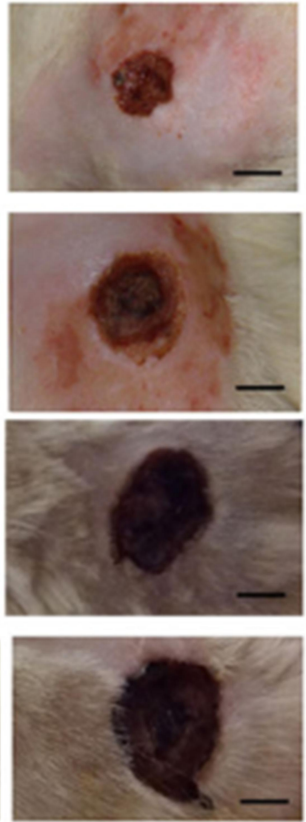

Day 4

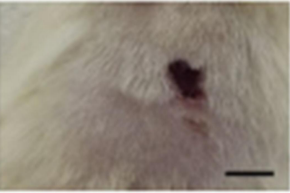

Arg-Lig-NFs (F6)

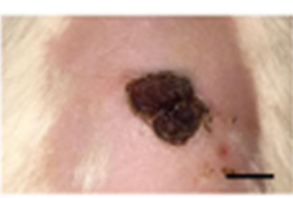

Lig-NFs (F5)

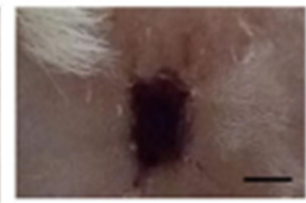

\section{Arginine solution}

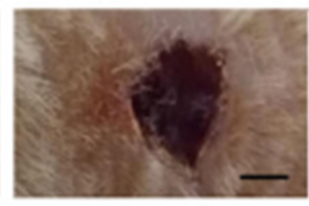

Day 9

Figure 14 Macroscopic images display wounds treated with different formulation on different time points. Reprinted by permission from Springer Nature, Drug Deliv Transl Res, Reesi F, Minaiyan M, Taheri A. A novel lignin-based nanofibrous dressing containing arginine for wound-healing applications, 8(I): I II-122, Copyright (20।8). ${ }^{103}$

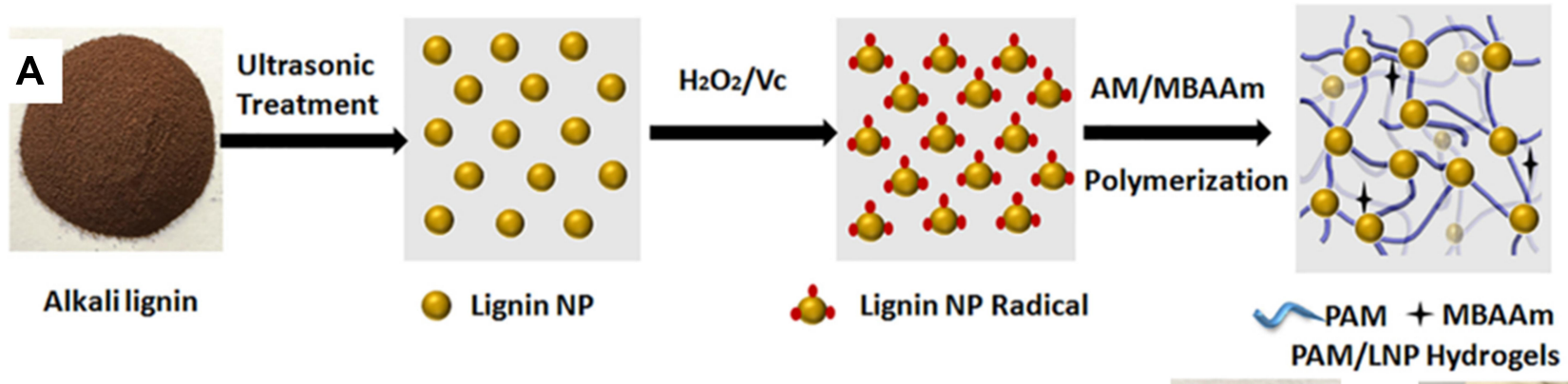

B

(1)<smiles>COCC(=O)C1OC(C(O)O)C(O)=C1O</smiles><smiles>O=C1OC(C(O)O)C(O)(O)[C@H]1O</smiles>

(2)
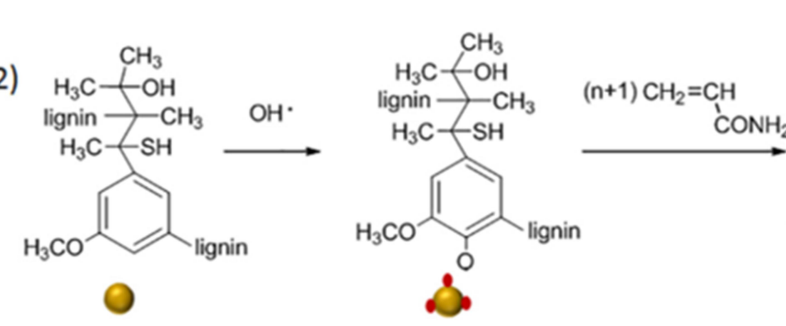
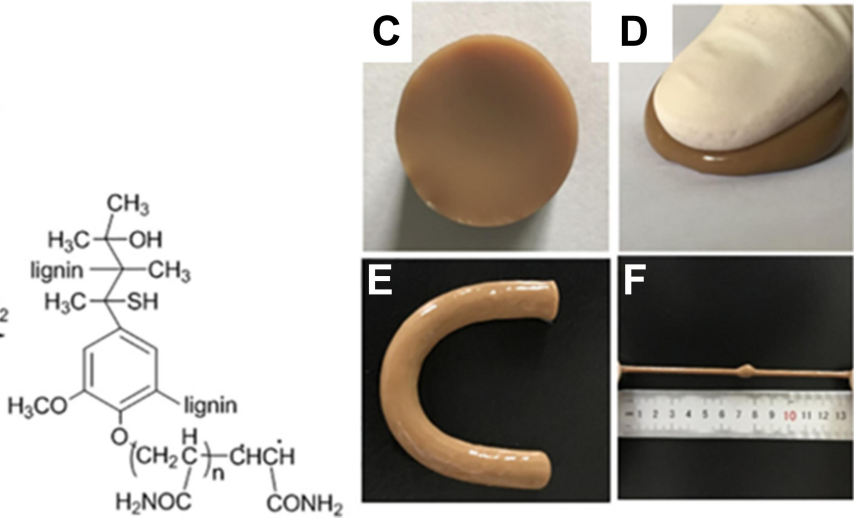

Figure 15 (A) PAM/LNP hydrogel fabrication procedure, (B) reaction of hydrogel formation; (C) hydrogel, (D) compressing, (E) bending, and (F) knotting images of hydrogels. Reprinted fromlnt J Biol Macromol, 128, Chen Y, Zheng K, Niu L, et al. Highly mechanical properties nanocomposite hydrogels with biorenewable lignin nanoparticles, 4I4-420, Copyright (2019), with permission from Elsevier. ${ }^{106}$

junctions) and polyacrylamide. Figure $15 \mathrm{~A}$ and $\mathrm{B}$ presents the formulation of hydrogel and reaction of formation of a hydrogel, respectively. ${ }^{106}$ The presence of lignin nanoparticles in the nanocomposite hydrogels enhances the mechanical properties of hydrogels as shown by high compressive, tensile strengths, and excellent recoverability. 
Figure 15C-F showed PAM/LNP hydrogel and its compressing, bending, and knotting photographs, respectively. ${ }^{106}$ A unique network structure and a strong hydrogen bonding between polyacrylamide chains and lignin nanoparticles provide an excellent mechanical property to nanocomposite hydrogels. In consideration of simple synthesis of polyacrylamide/lignin nanoparticle nanocomposite hydrogel methods and non-toxic along with good mechanical properties have made it the best candidate for tissue engineering, regeneration, and artificial muscles preparation applications. Berglund et $\mathrm{al}^{107}$ prepared aerogels based on lignincontaining arabinoxylan and cross-linked using citric acid and then reinforced with cellulose nanofibers. The samples were further lyophilized $\left(-20^{\circ} \mathrm{C}, 24 \mathrm{~h}\right)$ and heated $\left(120^{\circ} \mathrm{C}, 3\right.$ h) to promote cross-linking. The study results showed that the produced aerogels promote cell growth and new tissue formation owing to the highly porous, lightweight, and favorable network structure properties of aerogels. Moreover, the lignin-containing hemicellulose hydrogel platform could potentially be used for soft tissue engineering applications.

\section{Conclusion}

We have comprehensively reviewed the drug delivery and tissue engineering applications of lignin. The literature review suggested that lignin has an excellent physicochemical property, along with other important properties such as biocompatibility, biodegradability, renewable nature, feasibility to form nanoparticles, and encapsulation of drugs, which makes it a promising candidate in drug delivery and tissue engineering applications. Various protocols have been developed for nanoparticle formulations and used in the fabrication of drug delivery vehicles. More importantly, the antioxidant and antibacterial properties of lignin make it a valuable material in medicine. The scavenging nature of lignin towards oxygen radicals is an added advantage in drug-delivery to treat diseases that generate ROS.

Consequently, lignin can be utilized in ROS responsive carriers to deliver drugs against inflammatory bowel diseases. The ease in tunability of mechanical properties, feasibility to form nanocomposites with other polymers such as PCL, PLA, and its degradation. In addition to it, biocompatibility with a large range of cells accelerated its use in tissue engineering. Literature reports confirmed that lignin is a promising material in the formulation of bone scaffold and neural tissue engineering. However, further understanding of the mechanism of action needs to be investigated. We believe that there is a great scope for researchers to explore lignin use in other control and targeted drug delivery, tissue engineering, and other biomedical application.

\section{Acknowledgments}

Raj Kumar acknowledged the University of Nebraska Medical Center, USA. Arun Butreddy thankful to the University of Mississippi, USA. Nagavendra Kommineni thankful to Florida Agricultural and Mechanical University, USA. Chandrani Sarkar thankful to Mahila College, Kolhan University, Chaibasa, Jharkhand, India. Naveen Bunekar thankful to Chung Yuan Christian University, Taiwan. Sunil Dutt is very thankful to department of Chemistry, GC Daulatpur Chowk (Una, HP) and Department of Higher Education, Govt. of HP (Shimla, India). Keshaw Ram Aadil is grateful to the Science and Engineering Research Board (SERB), New Delhi, India for funding the NPDF project (PDF/2016/001156/LS). P. Guruprasad Reddy thankful to IISER, Tirupati for Postdoctoral Fellowship.

\section{Author Contributions}

All authors made a significant contribution to the work reported, whether that is in the conception, study design, execution, acquisition of data, analysis, and interpretation, or in all these areas; took part in drafting, revising, or critically reviewing the article; gave final approval of the version to be published; have agreed on the journal to which the article has been submitted; and agree to be accountable for all aspects of the work.

\section{Disclosure}

The authors report no conflicts of interest in this work.

\section{References}

1. Doherty WOS, Mousavioun P, Fellows CM. Value-adding to cellulosic ethanol: lignin polymers. Ind Crops Prod. 2011;33:259-276. doi:10.1016/j.indcrop.2010.10.022

2. Liu R, Dai L, Xu C, Wang K, Zheng C, Si C. Lignin-based micro- and nanomaterials and their composites in biomedical applications. ChemSusChem. 2020;13(17):4266-4283. doi:10.1002/cssc.202000783

3. Figueiredo P, Lintinen K, Hirvonen JT, Kostiainen MA, Santos HA. Properties and chemical modifications of lignin: towards lignin-based nanomaterials for biomedical applications. Prog Mater Sci. 2018;93:233-269. doi:10.1016/j.pmatsci.2017.12.001

4. Adler E. Lignin chemistry-past, present and future. Wood Sci Technol. 1977;11(3):169-218. doi:10.1007/BF00365615

5. Chen H, Gnanasekar P, Nair SS, Xu W, Chauhan P, Yan N. Lignin as a key component in lignin-containing cellulose nanofibrils for enhancing the performance of polymeric diphenylmethane diisocyanate wood adhesives. ACS Sustain Chem Eng. 2020;8(46):17165-17176. doi:10.1021/acssuschemeng.0c05642 
6. Gellerstedt G. Softwood kraft lignin: raw material for the future. Ind Crops Prod. 2015;77:845-854. doi:10.1016/j.indcrop.2015.09.040

7. Norgren M, Edlund H. Lignin: recent advances and emerging applications. Curr Opin Colloid Interface Sci. 2014;19 (5):409-416. doi:10.1016/j.cocis.2014.08.004

8. Thulluri C, Pinnamaneni SR, Shetty PR, Addepally U. Synthesis of lignin-based nanomaterials/nanocomposites: recent trends and future perspectives. Ind Biotechnol. 2016;12(3):153-160. doi:10.1089/ind.2015.0022

9. Notley SM, Norgren M. Lignin: functional biomaterial with potential in surface chemistry and nanoscience. Nanosci Technol Renew Biomater. 2009:173-205. John Wiley \& Sons, Ltd, Chichester, UK. doi:10.1002/9781444307474.ch7

10. Naseem A, Tabasum S, Zia KM, Zuber M, Ali M, Noreen A. Lignin-derivatives based polymers, blends and composites: a review. Int J Biol Macromol. 2016;93:296-313. doi:10.1016/j. ijbiomac.2016.08.030

11. Calvo-Flores FG, Dobado JA. Lignin as renewable raw material. ChemSusChem. 2010;3(11):1227-1235. doi:10.1002/cssc.201000157

12. Figueiredo $P$, Lintinen $K$, Kiriazis A, et al. In vitro evaluation of biodegradable lignin-based nanoparticles for drug delivery and enhanced antiproliferation effect in cancer cells. Biomaterials. 2017;121:97-108. doi:10.1016/j.biomaterials.2016.12.034

13. Frangville C, Rutkevičius M, Richter AP, Velev OD, Stoyanov SD, Paunov VN. Fabrication of environmentally biodegradable lignin nanoparticles. ChemPhysChem. 2012;13 (18):4235-4243. doi:10.1002/cphc.201200537

14. Domínguez-Robles J, Cárcamo-Martínez Á, Stewart SA, Donnelly RF, Larrañeta E, Borrega M. Lignin for pharmaceutical and biomedical applications - could this become a reality? Sustain Chem Pharm. 2020;18:100320. doi:10.1016/j.scp.20 20.100320

15. Thakur VK, Thakur MK, Raghavan P, Kessler MR. Progress in green polymer composites from lignin for multifunctional applications: a review. ACS Sustain Chem Eng. 2014;2:1072-1092. doi: $10.1021 / \mathrm{sc} 500087 \mathrm{z}$

16. Sipponen $\mathrm{MH}$, Lange $\mathrm{H}$, Crestini $\mathrm{C}$, Henn A, Österberg $\mathrm{M}$. Lignin for nano- and microscaled carrier systems: applications, trends, and challenges. ChemSusChem. 2019;12(10):2039-2054. doi:10.1002/cssc.201900480

17. Kai D, Tan MJ, Chee PL, Chua YK, Yap YL, Loh XJ. Towards lignin-based functional materials in a sustainable world. Green Chem. 2016;18(5):1175-1200. doi:10.1039/c5gc02616d

18. Ganewatta MS, Lokupitiya HN, Tang C. Lignin biopolymers in the age of controlled polymerization. Polymers (Basel). 2019;11 (7):1176. doi:10.3390/polym 11071176

19. Bertella S, Luterbacher JS. Lignin functionalization for the production of novel materials. Trends Chem. 2020;2(5):440-453. doi:10.1016/j.trechm.2020.03.001

20. Chio C, Sain M, Qin W. Lignin utilization: a review of lignin depolymerization from various aspects. Renew Sustain Energy Rev. 2019;107:232-249. doi:10.1016/j.rser.2019.03.008

21. Li C, Zhao X, Wang A, Huber GW, Zhang T. Catalytic transformation of lignin for the production of chemicals and fuels. Chem Rev. 2015;115(21):11559-11624. doi:10.1021/acs.chemrev.5b00155

22. Dai L, Cao Q, Wang K, et al. High efficient recovery of L-lactide with lignin-based filler by thermal degradation. Ind Crops Prod. 2020;143:111954. doi:10.1016/j.indcrop.2019.111954

23. Dai L, Liu R, Hu LQ, Zou ZF, Si CL. Lignin nanoparticle as a novel green carrier for the efficient delivery of resveratrol. ACS Sustain Chem Eng. 2017;5(9):8241-8249. doi:10.1021/ acssuschemeng.7b01903

24. Wang W, Wang X, Ma Z, et al. Breaking the lignin conversion bottleneck for multiple products: co-production of aryl monomers and carbon nanospheres using one-step catalyst-free depolymerization. Fuel. 2021;285:119211. doi:10.1016/j.fuel.2020.119211
25. Iravani S, Varma RS. Greener synthesis of lignin nanoparticles and their applications. Green Chem. 2020;22(3):612-636. doi:10.1039/c9gc02835h

26. Lizundia E, Armentano I, Luzi F, et al. Synergic effect of nanolignin and metal oxide nanoparticles into Poly(l-lactide) bionanocomposites: material properties, antioxidant activity, and antibacterial performance. ACS Appl Bio Mater. 2020;3 (8):5263-5274. doi:10.1021/acsabm.0c00637

27. Chen F, Dai H, Dong X, Yang J, Zhong M. Physical properties of lignin-based polypropylene blends. Polym Compos. 2011;32 (7):1019-1025. doi:10.1002/pc.21087

28. El Mansouri NE, Pizzi A, Salvado J. Lignin-based polycondensation resins for wood adhesives. J Appl Polym Sci. 2007;103 (3):1690-1699. doi:10.1002/app.25098

29. Qian Y, Zhang Q, Qiu X, Zhu S. CO2-responsive diethylaminoethyl-modified lignin nanoparticles and their application as surfactants for $\mathrm{CO} 2 / \mathrm{N} 2$-switchable pickering emulsions. Green Chem. 2014;16(12):4963-4968. doi:10.1039/c4gc01242a

30. Lievonen M, Valle-Delgado JJ, Mattinen ML, et al. A simple process for lignin nanoparticle preparation. Green Chem. 2016;18(5):1416-1422. doi:10.1039/c5gc01436k

31. Richter AP, Brown JS, Bharti B, et al. An environmentally benign antimicrobial nanoparticle based on a silver-infused lignin core. Nat Nanotechnol. 2015;10(9):817-823. doi:10.1038/nnano.2015.141

32. Nypelö TE, Carrillo CA, Rojas OJ. Lignin supracolloids synthesized from $(\mathrm{W} / \mathrm{O})$ microemulsions: use in the interfacial stabilization of pickering systems and organic carriers for silver metal. Soft Matter. 2015;11(10):2046-2054. doi:10.1039/c4sm02851a

33. Machhi J, Shahjin F, Das S, et al. Kevadiya, Nanocarrier Vaccines for SARS-CoV-2. Advanced Drug Delivery Reviews. 2021. doi:10.1016/j.addr.2021.01.002

34. Kumar R, Gupta A, Chawla M, et al. Advances in nanotechnology based strategies for synthesis of nanoparticles of lignin. In: Lignin. Cham: Springer;2020:203-229. doi:10.1007/978-3-030-40663-9_7

35. Kumar R, Singh A, Sharma K, Dhasmana D, Garg N, Siril PF. Preparation, characterization and in vitro cytotoxicity of fenofibrate and nabumetone loaded solid lipid nanoparticles. Mater Sci Eng C. 2020;106:110184. doi:10.1016/j.msec.2019.110184

36. Kumar R, Siril PF. Preparation and characterization of polyvinyl alcohol stabilized griseofulvin nanoparticles. Mater Today Proc. 2016;3(6):2261-2267. Elsevier Ltd. doi:10.1016/j.matpr.20 16.04 .135

37. Kumar R. Nanotechnology based approaches to enhance aqueous solubility and bioavailability of griseofulvin: a literature survey. J Drug Deliv Sci Technol. 2019;53:101221. doi:10.1016/j.jddst.201 9.101221

38. Kumar R, Siril PF. Drop-by-drop solvent hot antisolvent interaction method for engineering nanocrystallization of sulfamethoxazole to enhanced water solubility and bioavailability. J Drug Deliv Sci Technol. 2020;55:101359. doi:10.1016/j.jddst.2019.101359

39. Kumar R, Dalvi SV, Siril PF. Nanoparticle-based drugs and formulations: current status and emerging applications. ACS Appl Nano Mater. 2020;3(6):4944-4961. doi:10.1021/acsanm.0c00606

40. Kumar R. Solubility and bioavailability of fenofibrate nanoformulations. ChemistrySelect. 2020;5(4):1478-1490. doi:10.1002/slct.201903647

41. Gilca IA, Popa VI, Crestini C. Obtaining lignin nanoparticles by sonication. Ultrason Sonochem. 2015;23:369-375. doi:10.1016/j. ultsonch.2014.08.021

42. Lindströmn T. The colloidal behaviour of kraft lignin - part I.: association and gelation of kraft lignin in aqueous solutions. Colloid Polym Sci. 1979;257:277-285. doi:10.1007/BF01382370

43. Vainio U, Maximova N, Hortling B, et al. Morphology of dry lignins and size and shape of dissolved kraft lignin particles by X-ray scattering. Langmuir. 2004;20(22):9736-9744. doi:10.102 $1 / \mathrm{la} 048407 \mathrm{v}$ 
44. Moreva YL, Alekseeva NS, Chernoberezhskii YM. Histograms of the size distribution of kraft lignin particles in aqueous solutions at various pH values. Russ J Appl Chem. 2010;83(7):1281-1283. doi:10.1134/S1070427210070207

45. Sipponen MH, Lange H, Ago M, Crestini C. Understanding lignin aggregation processes. a case study: budesonide entrapment and stimuli controlled release from lignin nanoparticles. ACS Sustain Chem Eng. 2018;6(7):9342-9351. doi:10.1021/acssuschemeng.8b01652

46. Rangan A, Manchiganti MV, Thilaividankan RM, Kestur SG, Menon R. Novel method for the preparation of lignin-rich nanoparticles from lignocellulosic fibers. Ind Crops Prod. 2017;103:152-160. doi:10.1016/j.indcrop.2017.03.037

47. Kumar R, Soni P, Siril PF. Engineering the morphology and particle size of high energetic compounds using drop-by-drop and drop-to-drop solvent-antisolvent interaction methods. ACS Omega. 2019;4(3):5424-5433. doi:10.1021/acsomega.8b03214

48. Yiamsawas D, Beckers SJ, Lu H, Landfester K, Wurm FR. Morphology-controlled synthesis of lignin nanocarriers for drug delivery and carbon materials. ACS Biomater Sci Eng. 2017;3 (10):2375-2383. doi:10.1021/acsbiomaterials.7b00278

49. Nair SS, Sharma S, Pu Y, et al. High shear homogenization of lignin to nanolignin and thermal stability of nanolignin-polyvinyl alcohol blends. ChemSusChem. 2014;7(12):3513-3520. doi:10.1002/cssc. 201402314

50. Alqahtani MS, Alqahtani A, Al-Thabit A, Roni M, Syed R. Novel lignin nanoparticles for oral drug delivery. $J$ Mater Chem B. 2019;7(28):4461-4473. doi:10.1039/c9tb00594c

51. Liu X, Yin H, Zhang Z, Diao B, Li J. Functionalization of lignin through ATRP grafting of poly(2-dimethylaminoethyl methacrylate) for gene delivery. Colloids Surf $B$ Biointerfaces. 2015;125:230-237. doi:10.1016/j.colsurfb.2014.11.018

52. Kumar R, Siril PF, Javid F. Unusual anti-leukemia activity of nanoformulated naproxen and other non-steroidal anti-inflammatory drugs. Materials Science and Engineering C. 69 2016;1335-1344. doi:10.1016/j.msec.2016.08.024

53. Kumar R, Singh A, Garg N, Siril PF. Solid lipid nanoparticles for the controlled delivery of poorly water soluble non-steroidal antiinflammatory drugs. Ultrasonics Sonochemistry. 40 2018;686-696. doi:10.1016/j.ultsonch.2017.08.018

54. Vetvicka D, Sivak L, Jogdeo CM, et al. Gene silencing delivery systems for the treatment of pancreatic cancer: Where and what to target next? Journal of Controlled Release. 331 2021;246-259. doi:10.1016/j.jconrel.2021.01.020

55. Lü J-M, Wang X, Marin-Muller C, et al. Current advances in research and clinical applications of PLGA-based nanotechnology. Expert Rev Mol Diagn. 2009;9(4):325-341. doi:10.1586/erm.09.15

56. Byrne CE, Astete CE, Vaithiyanathan M, et al. Lignin-graftPLGA drug-delivery system improves efficacy of MEK1/2 inhibitors in triple-negative breast cancer cell line. Nanomedicine. 2020;15(10):981-1000. doi:10.2217/nnm-2020-0010

57. Figueiredo P, Ferro C, Kemell M, et al. Functionalization of carboxylated lignin nanoparticles for targeted and $\mathrm{pH}$-responsive delivery of anticancer drugs. Nanomedicine. 2017;12 (21):2581-2596. doi:10.2217/nnm-2017-0219

58. Zhou Y, Han Y, Li G, Yang S, Xiong F, Chu F. Preparation of targeted lignin-based hollow nanoparticles for the delivery of doxorubicin. Nanomaterials. 2019;9(2):188. doi:10.3390/nano9020188

59. Chen S, Wang G, Sui W, Parvez AM, Si C. Synthesis of lignin-functionalized phenolic nanosphere supported Ag nanoparticles with excellent dispersion stability and catalytic performance. Green Chem. 2020;22(9):2879-2888. doi:10.1039/ c9gc04311j

60. Yan Z, Liao G, Zou X, et al. Size-controlled and super long-term stable lignin nanospheres through a facile self-assembly strategy from kraft lignin. J Agric Food Chem. 2020;68(31):8341-8349. doi:10.1021/acs.jafc.0c01262
61. Tiwari A, Kumar R, Shefi O, Randhawa JK. Fluorescent mantle carbon coated core-shell SPIONs for neuroengineering applications. ACS Appl Bio Mater. 2020;3(7):4665-4673. doi:10.1021/acsabm.0c00582

62. Kumar R, Mondal K, Panda PK, et al. Core-shell nanostructures: perspectives towards drug delivery applications. J Mater Chem B. 2020;8:8992-9027. doi:10.1039/d0tb01559h

63. Tortora M, Cavalieri F, Mosesso P, Ciaffardini F, Melone F, Crestini C. Ultrasound driven assembly of lignin into microcapsules for storage and delivery of hydrophobic molecules. Biomacromolecules. 2014;15(5):1634-1643. doi:10.1021/ bm500015j

64. Chen N, Dempere LA, Tong Z. Synthesis of pH-responsive lignin-based nanocapsules for controlled release of hydrophobic molecules. ACS Sustain Chem Eng. 2016;4(10):5204-5211. doi:10.1021/acssuschemeng.6b01209

65. Sipponen MH, Henn A, Penttilä P, Österberg M. Lignin-fatty acid hybrid nanocapsules for scalable thermal energy storage in phase-change materials. Chem Eng J. 2020;393:124711. doi:10.1016/j.cej.2020.124711

66. Wei Z, Yang Y, Yang R, Wang C. Alkaline lignin extracted from furfural residues for $\mathrm{pH}$-responsive pickering emulsions and their recyclable polymerization. Green Chem. 2012;14(11):3230-3236. doi:10.1039/c2gc36278c

67. Sipponen MH, Farooq M, Koivisto J, Pellis A, Seitsonen J, Österberg M. Spatially confined lignin nanospheres for biocatalytic ester synthesis in aqueous media. Nat Commun. 2018;9(1). doi:10.1038/s41467-018-04715-6

68. Sipponen MH, Smyth M, Leskinen T, Johansson LS, Österberg M. All-lignin approach to prepare cationic colloidal lignin particles: stabilization of durable pickering emulsions. Green Chem. 2017;19(24):5831-5840. doi:10.1039/c7gc02900d

69. Dai L, Li Y, Kong F, Liu K, Si C, Ni Y. Lignin-based nanoparticles stabilized pickering emulsion for stability improvement and thermal-controlled release of trans-resveratrol. ACS Sustain Chem Eng. 2019;7(15):13497-13504. doi:10.1021/acssuschemen g.9b02966

70. Mahata D, Jana M, Jana A, et al. Lignin-graft-polyoxazoline conjugated triazole a novel anti-infective ointment to control persistent inflammation. Sci Rep. 2017;7(1):1-16. doi:10.1038/ srep46412

71. Ravishankar K, Venkatesan M, Desingh RP, et al. Biocompatible hydrogels of chitosan-alkali lignin for potential wound healing applications. Mater Sci Eng C. 2019;102:447-457. doi:10.1016/j. msec.2019.04.038

72. Farhat W, Venditti R, Mignard N, Taha M, Becquart F, Ayoub A. Polysaccharides and lignin based hydrogels with potential pharmaceutical use as a drug delivery system produced by a reactive extrusion process. Int J Biol Macromol. 2017;104:564-575. doi:10.1016/j.ijbiomac.2017.06.037

73. Li Y, Qiu X, Qian Y, Xiong W, Yang D. pH-responsive lignin-based complex micelles: preparation, characterization and application in oral drug delivery. Chem Eng J. 2017;327:1176-1183. doi:10.1016/j.cej.2017.07.022

74. Cheng L, Deng B, Luo W, et al. pH-responsive lignin-based nanomicelles for oral drug delivery. $J$ Agric Food Chem. 2020;68(18):5249-5258. doi:10.1021/acs.jafc.9b08171

75. Morganti P, Danti S, Coltelli MB. Chitin and lignin to produce biocompatible tissues. Res Clin Dermatol. 2018;01(01). doi:10.35841/clinical-dermatology.1.1.5-11

76. Witzler M, Alzagameem A, Bergs M, et al. Lignin-derived biomaterials for drug release and tissue engineering. Molecules. 2018;23(8):1885. doi:10.3390/molecules23081885

77. Keane TJ, Badylak SF. Biomaterials for tissue engineering applications. Semin Pediatr Surg. 2014;23(3):112-118. doi:10.1053/j.sempedsurg.2014.06.010 
78. Drury JL, Mooney DJ. Hydrogels for tissue engineering: scaffold design variables and applications. Biomaterials. 2003;24 (24):4337-4351. doi:10.1016/S0142-9612(03)00340-5

79. De Moraes MA, Da Silva CF, Vieira RS, editors. Biopolymer Membranes and Films. Elsevier; 2020. doi:10.1016/c20180-02693-6

80. Kai D, Ren W, Tian L, et al. Engineering poly(lactide)-lignin nanofibers with antioxidant activity for biomedical application. ACS Sustain Chem Eng. 2016;4(10):5268-5276. doi:10.1021/ acssuschemeng.6b00478

81. Ma Z, Kotaki M, Inai R, Ramakrishna S. Potential of nanofiber matrix as tissue-engineering scaffolds. Tissue Eng. 2005;11(1-2):101-109. doi:10.1089/ten.2005.11.101

82. Kumar R, Aadil KR, Ranjan S, Kumar VB. Advances in nanotechnology and nanomaterials based strategies for neural tissue engineering. J Drug Deliv Sci Technol. 2020;57:101617. doi:10.1016/j.jddst.2020.101617

83. Saudi A, Amini S, Amirpour N, et al. Promoting neural cell proliferation and differentiation by incorporating lignin into electrospun poly(vinyl alcohol) and poly(glycerol sebacate) fibers. Mater Sci Eng C. 2019;104:110005. doi:10.1016/j.msec.20 19.110005

84. Vijayavenkataraman S, Thaharah S, Zhang S, Lu WF, Fuh JYH. Electrohydrodynamic jet 3D-printed PCL/PAA conductive scaffolds with tunable biodegradability as nerve guide conduits (NGCs) for peripheral nerve injury repair. Mater Des. 2019;162:171-184. doi:10.1016/j.matdes.2018.11.044

85. Sant S, Iyer D, Gaharwar AK, Patel A, Khademhosseini A. Effect of biodegradation and de novo matrix synthesis on the mechanical properties of valvular interstitial cell-seeded polyglycerol sebacate-polycaprolactone scaffolds. Acta Biomater. 2013;9 (4):5963-5973. doi:10.1016/j.actbio.2012.11.014

86. de Ruiter GCW, Malessy MJA, Yaszemski MJ, et al. Designing ideal conduits for peripheral nerve repair. Neurosurg Focus. 2009;26(2):1-9. doi:10.3171/FOC.2009.26.2.E5

87. Ugartondo V, Mitjans M, Vinardell MP. Applicability of lignins from different sources as antioxidants based on the protective effects on lipid peroxidation induced by oxygen radicals. Ind Crops Prod. 2009;30(2):184-187. doi:10.1016/j.indcrop.20 09.03.001

88. Ito Y, Shimazawa M, Akao Y, et al. Lig-8, a bioactive lignophenol derivative from bamboo lignin, protects against neuronal damage in vitro and in vivo. J Pharmacol Sci. 2006;102(2):196-204. doi:10.1254/jphs.FP0060711

89. Amini S, Saudi A, Amirpour N, et al. Application of electrospun polycaprolactone fibers embedding lignin nanoparticle for peripheral nerve regeneration: in vitro and in vivo study. Int $\mathrm{J} \mathrm{Biol}$ Macromol. 2020;159:154-173. doi:10.1016/j.ijbiomac.2020.05.073

90. Salami MA, Kaveian F, Rafienia M, Saber-Samandari S, Khandan A, Naeimi M. Electrospun polycaprolactone/lignin-based nanocomposite as a novel tissue scaffold for biomedical applications. J Med Signals Sens. 2017;7(4):228-238. doi:10.4103/jmss.JMSS_11_17

91. Wang D, Jang J, Kim K, Kim J, Park CB. "Tree to bone": lignin/ polycaprolactone nanofibers for hydroxyapatite biomineralization. Biomacromolecules. 2019;20(7):2684-2693. doi:10.1021/acs. biomac.9b00451

92. Kai D, Jiang S, Low ZW, Loh XJ. Engineering highly stretchable lignin-based electrospun nanofibers for potential biomedical applications. J Mater Chem B. 2015;3(30):6194-6204. doi:10.1039/c5tb00765h

93. Collins MN, Nechifor M, Tanasă F, et al. Valorization of lignin in polymer and composite systems for advanced engineering applications - a review. Int J Biol Macromol. 2019;131:828-849. doi:10.1016/j.ijbiomac.2019.03.069
94. Kai D, Zhang K, Jiang L, et al. Sustainable and antioxidant lignin-polyester copolymers and nanofibers for potential healthcare applications. ACS Sustain Chem Eng. 2017;5(7):6016-6025. doi:10.1021/acssuschemeng.7b00850

95. Ravichandran R, Venugopal JR, Sundarrajan S, Mukherjee S, Ramakrishna S. Precipitation of nanohydroxyapatite on PLLA/ PBLG/collagen nanofibrous structures for the differentiation of adipose derived stem cells to osteogenic lineage. Biomaterials. 2012;33(3):846-855. doi:10.1016/j.biomaterials.2011.10.030

96. Kim M, Yeo M, Kim M, Kim G. Biomimetic cellulose/calcium-deficient-hydroxyapatite composite scaffolds fabricated using an electric field for bone tissue engineering. RSC $A d v$. 2018;8 (37):20637-20647. doi:10.1039/c8ra03657h

97. Lange H, Decina S, Crestini C. Oxidative upgrade of lignin recent routes reviewed. Eur Polym J. 2013;49(6):1151-1173. doi:10.1016/j.eurpolymj.2013.03.002

98. Dizhbite T, Telysheva G, Jurkjane V, Viesturs U. Characterization of the radical scavenging activity of lignins - natural antioxidants. Bioresour Technol. 2004;95(3):309-317. doi:10.1016/j.biortech.2004.02.024

99. Ugartondo V, Mitjans M, Vinardell MP. Comparative antioxidant and cytotoxic effects of lignins from different sources. Bioresour Technol. 2008;99(14):6683-6687. doi:10.1016/j.biortech.2007.11.038

100. Wang J, Tian L, Luo B, et al. Engineering PCL/lignin nanofibers as an antioxidant scaffold for the growth of neuron and schwann cell. Colloids Surf B Biointerfaces. 2018;169:356-365. doi:10.1016/j.colsurfb.2018.05.021

101. Genes NG, Rowley JA, Mooney DJ, Bonassar LJ. Effect of substrate mechanics on chondrocyte adhesion to modified alginate surfaces. Arch Biochem Biophys. 2004;422(2):161-167. doi:10.1016/j.abb.2003.11.023

102. Rowley JA, Madlambayan G, Mooney DJ. Alginate hydrogels as synthetic extracellular matrix materials. Biomaterials. 1999;20 (1):45-53. doi:10.1016/S0142-9612(98)00107-0

103. Reesi F, Minaiyan M, Taheri A. A novel lignin-based nanofibrous dressing containing arginine for wound-healing applications. Drug Deliv Transl Res. 2018;8(1):111-122. doi:10.1007/s13346017-0441-0

104. Quraishi S, Martins M, Barros AA, et al. Novel non-cytotoxic alginatelignin hybrid aerogels as scaffolds for tissue engineering. J Supercrit Fluids. 2015;105:1-8. doi:10.1016/j.supflu.2014.12.026

105. Raschip IE, Vasile C, Ciolacu D, Cazacu G. Semi-interpenetrating polymer networks containing polysaccharides. i xanthan/lignin networks. High Perform Polym. 2007;19(5-6):603-620. doi:10.1177/0954008307081202

106. Chen Y, Zheng K, Niu L, et al. Highly mechanical properties nanocomposite hydrogels with biorenewable lignin nanoparticles. Int J Biol Macromol. 2019;128:414 420. doi:10.1016/j.ijbiomac.2019.01.099

107. Berglund L, Forsberg F, Jonoobi M, Oksman K. Promoted hydrogel formation of lignin-containing arabinoxylan aerogel using cellulose nanofibers as a functional biomaterial. RSC Adv. 2018;8(67):38219-38228. doi:10.1039/c8ra08166b

108. Quraishi S, Martins M, Barros AA, et al. Novel non-cytotoxic alginate-lignin hybrid aerogels as scaffolds for tissue engineering. J. Supercrit Fluids. 105 (2015); 1-8. doi:10.1016/j. supflu.2014.12.026

109. Chen Y, Zheng K, Niu L, et al. Highly mechanical properties nanocomposite hydrogels with biorenewable lignin nanoparticles. Int. J. Biol. Macromol. 128 (2019); 414-420. doi:10.1016/j. ijbiomac.2019.01.099

110. Liang $\mathrm{R}$, Zhao J, Li B, et al. Implantable and degradable antioxidant poly( $\varepsilon$-caprolactone)-lignin nanofiber membrane for effective osteoarthritis treatment. Biomaterials. 230 (2020); 119601. doi:10.1016/j.biomaterials.2019.119601

111. Zhang Y, Jiang M, Zhang Y, et al. Novel lignin-chitosan-PVA composite hydrogel for wound dressing, Mater. Sci. Eng. C. 104 (2019); 110002. doi:10.1016/j.msec.2019.110002 


\section{Publish your work in this journal}

The International Journal of Nanomedicine is an international, peerreviewed journal focusing on the application of nanotechnology in diagnostics, therapeutics, and drug delivery systems throughout the biomedical field. This journal is indexed on PubMed Central, MedLine, CAS, SciSearch ${ }^{\mathbb{B}}$, Current Contents ${ }^{\mathbb{B}} /$ Clinical Medicine,
Journal Citation Reports/Science Edition, EMBase, Scopus and the Elsevier Bibliographic databases. The manuscript management system is completely online and includes a very quick and fair peer-review system, which is all easy to use. Visit http://www.dovepress.com/ testimonials.php to read real quotes from published authors.

Submit your manuscript here: https://www.dovepress.com/international-journal-of-nanomedicine-journal 